Article

\title{
Hydrological Implications of Climate Change on River Basin Water Cycle: Case Studies of the Yangtze River and Yellow River Basins, China
}

\author{
Liu Liu ${ }^{1, *}$, Zongxue $\mathrm{Xu}^{2}$, Rong $\mathrm{Li}^{1}$ and Youzhi Wang ${ }^{1}$ \\ 1 College of Water Resources and Civil Engineering, China Agricultural University, \\ Center for Agricultural Water Research in China, Beijing 100083, China \\ 2 College of Water Sciences, Beijing Normal University, Joint Center for Global Change Studies (JCGCS), \\ Beijing 100875, China; zxxu@bnu.edu.cn \\ * Correspondence: liuliu@cau.edu.cn; Tel.: +86-10-6273-7144
}

\begin{abstract}
Climate change is a global issue that draws widespread attention from the international society. As an important component of the climate system, the water cycle is directly affected by climate change. Thus, it is very important to study the influences of climate change on the basin water cycle with respect to maintenance of healthy rivers, sustainable use of water resources, and sustainable socioeconomic development in the basin. In this study, by assessing the suitability of multiple General Circulation Models (GCMs) recommended by the Intergovernmental Panel on Climate Change, Statistical Downscaling Model (SDSM) and Automated Statistical Downscaling model (ASD) were used to generate future climate change scenarios. These were then used to drive distributed hydrologic models (Variable Infiltration Capacity, Soil and Water Assessment Tool) for hydrological simulation of the Yangtze River and Yellow River basins, thereby quantifying the effects of climate change on the basin water cycle. The results showed that suitability assessment adopted in this study could effectively reduce the uncertainty of GCMs, and that statistical downscaling was able to greatly improve precipitation and temperature outputs in global climate mode. Compared to a baseline period (1961-1990), projected future periods (2046-2065 and 20812100) had a slightly decreasing tendency of runoff in the lower reaches of the Yangtze River basin. In particular, a significant increase in runoff was observed during flood seasons in the southeast part. However, runoff of the upper Yellow River basin decreased continuously. The results provide a reference for studying climate change in major river basins of China.
\end{abstract}

Keywords: climate change; water cycle; downscaling; hydrological model; Yangtze River; Yellow River; Tibetan Plateau

\section{Introduction}

The Fifth Assessment Report (AR5) [1] of the Intergovernmental Panel on Climate Change (IPCC) pointed out that climate change has become an indisputable fact that will greatly threaten global and local water resource security. In China, the tendency of climate change has been generally consistent with its global pattern [2-3]. The multiscale, all-dimension, multi-level influences of climate change on humans, the ecology and environment [4-11] are key risk factors for global sustainable development. Because the water cycle connects humans, the ecology and environment, its response to future climate change has become a focus of scientists, the general public, and decision-makers all over the world.

China has a vast territory and various climate types. Because of substantial differences in geological environment, climate, and economic development stages in various regions, the influences of climate change vary. In the context of global warming, the frequency and intensity of climate extremes such as high temperature, low temperature, heavy precipitation and droughts in China had varying tendencies and regional differences [12-13]. Recently, a number of researchers 
have conducted extensive studies of climate change and its effects on water resources in China. In general, it was found that over the past 100 years, hydrological climate elements changed substantially in major basins of the country, showing substantial temperature rises in most areas. In the last 50 years, there has been an uneven south-north precipitation distribution in the eastern monsoon region [14-17] and reduced basin runoff in the majority of northern exorheic rivers, aggravating water resource supply-demand conflicts in the north and pressure for flood control in the south [18-20]. In most regions of the country, the potential (water surface) evaporation capability decreased dramatically [21-24]. Future climate change might exert strong impacts on water resources in China [25-28], with reduced runoff in northern rivers but increased runoff in southern ones [29]. Annual average evaporation may be on the rise [30], as may be the case also for the frequency of flood and drought disasters, which would further increase the vulnerability of water resources and conflict between water supply and demand [29].

Because of basin water cycle and water resource pattern changes in major river basins of China and prominent water issues such as flood disasters in the south and water shortages in the north, it is of great scientific importance and value to study the mechanism and spatiotemporal variation of the continental water cycle under the background of climate change. This will help assess the influence of such change on the basin water cycle and ensure sustainable socioeconomic development in the country.

In the current study, basins of the Yangtze River and Yellow River were selected to represent typical southern and northern basins in China. A multi-criteria score-based method was used to assess the suitability of multiple General Circulation Models (GCMs) provided by the IPCC. Screened GCM output results were downscaled to create future climate change scenarios suitable for the Yangtze and Yellow River basins. These scenarios were used to drive distributed hydrological models to simulate the spatiotemporal variation of water cycle elements in the study area, thereby evaluating the response of the river basin water cycle to future climate change.

\section{Materials and Methods}

\subsection{GCM suitability assessment method}

Taking the degree of fit of statistical values from GCM output and those from field-measured data as objective functions, the performance of each such function was scored, thereby evaluating the comprehensive performance of GCMs.

The mean value, coefficient of variability (= standard deviation / mean value), and normalized root mean square error (NRMSE) were used to characterize closeness between the mean value and deviation of GCM output variables and those of measured variables. NRMSE was defined as the ratio of root mean square error to the corresponding standard deviation.

Pearson correlation coefficients in both chronological (multiyear average monthly sequence) and spatial (mean value of climate elements at stations) sequences were used to characterize the closeness between GCM simulation and measured values, thereby evaluating the simulated variables' intraannual change and spatial degree of fit.

The rank-based nonparametric Mann-Kendall method was used to detect long-term tendencies (MK Zc) and magnitudes (MK Slope) of every variable. If areas where the MK Zc of GCM output variables matched measured values did not reach 95\%, MK Slope was not included in the scoring.

Empirical orthogonal functions (EOFs) were used to qualitatively and quantitatively characterize variable spatiotemporal variation. Preliminary analysis showed that the first and second EOF characteristic vectors of nearly 20 variables were able to explain most of the deviations. Hence, these two vectors were included in rank scoring.

Two statistics of the probability density function, Brier score (BS) and skill score (Sscore), were used to evaluate the effectiveness of GCM simulation of that function. BS is the mean square deviation of probabilistic prediction, and Sscore is used to describe the overlap between the computed and measured probability distribution. 
A total of 11 statistics were included, i.e., mean, coefficient of variability, NRMSE, temporal correlation coefficient, spatial correlation coefficient, trend analysis rank statistics, trend analysis variation magnitude, first and second EOF characteristic vectors, and BS and Sscore of the probability density function. Performance of each of the statistics was considered as one of the objective functions. A multi-criteria rank score (RS) value was computed for every objective function by assigning a value of $0-10$, based on GCM performance. The calculation was

$$
R S_{i}=\operatorname{Int}\left[\frac{x_{i}-x_{\min }}{x_{\max }-x_{\min }} * 10\right], x_{i}<x_{\max }
$$

where $x_{i}$ is relative error in a statistic between simulated and measured values. The smaller the value is, the lower the score is. For a specific GCM output variable, the final total score was calculated by averaging the scores of all statistics. The better the simulation results, the lower the score. The score represents the degree of fit between GCMs outputs and measured values. It could be used to compare and analyze different GCMs, but it does not indicate the actual simulation accuracy of a given GCM.

\subsection{Downscaling model}

The Statistical Downscaling Model (SDSM) has both of deterministic transfer functions and stochastic components [31](Wilby, R.L., C.W. Dawson and E.M. Barrow, SDSM-A decision support tool for the assessment of regional climate change impacts. Environmental Modelling \& Software, 2002. 17(2): p. 145-157.). It has been widely applied in the statistical downscaling studies for both climate variables and air quality variables, and has been recommended by the Canadian Climate Impacts and Scenarios (CCIS) project (http://www.cics.uvic.ca).

An automated regression-based statistical downscaling model (ASD), [32] (Hessami, M., Gachon, P., Ouarda, T.B.M.J. and St-Hilaire, A., (2008) Automated regression-based Statistical Downscaling tool, Environmental Modelling and Software, 23, 813-834.), inspired by the existing SDSM was developed within the Matlab environment, which is an easy to use graphical user interface for the statistical downscaling of GCM outputs to regional or local variables and already been successfully applied in major river basins of the east monsoon region in China [33] (Xu ZX, Liu P, Liu WF. Automated statistical downscaling in several river basins of the Eastern Monsoon region, China. Proceedings of H01, IAHS-IAPSO-IASPEI Assembly, Gothenburg, Sweden, 2013 (IAHS Publ. 359, 2013), 80-85).

\subsection{Distributed hydrological models}

The Taihu basin, located in the Yangtze River Delta region, is selected as the typical area for hydrological modeling in this study, which is characterized by a flat terrain, a complex river network, and various polder areas, without a clear outlet. Based on a 90-m DEM, it is difficult to extract the basin river network and simulate runoff yield and concentration over the entire basin. Therefore, the distributed Variable Infiltration Capacity (VIC) model based on grids was used to directly obtain gridded runoff depth in the basin. The VIC model considers physical exchange processes of atmosphere-vegetation-soil, primarily reflected by the variation of water and heat conditions and water and heat transfer in those three components. The model has been widely used to study the effects of climate change on hydrologic processes [34-39]. VIC can either simultaneously simulate atmospheric-hydrological energy balance and water balance, or just calculate water balance, export runoff depth, and evaporation at each grid. Through a runoff concentration model, it transforms grid runoff depth into water flow at the basin outlet, eliminating the shortcomings of traditional hydrological models in the description of thermal processes.

The upper reaches of the Yellow River basin were selected to investigate the influences of climate change on the basin water cycle in this study. The reasons for this selection were: (1) The upper reaches are the origin of the Yellow River, and runoff variation there affects the entire basin; (2) future runoff change in the upper reaches can be used to validate basin-wide runoff change; (3) results of sub-basin estimation can provide accurate and detailed information for future runoff 
variation tendencies. In the upper reaches of the Yellow River basin, there is strong terrain fluctuation, an extractable river network, and abundant hydrologic data for the basin outlet. The Soil and Water Assessment Tool (SWAT) model [40-41] was used for distributed hydrological simulation. Parameter sensitivity was analyzed by use of the built-in sensitivity analysis module.

\subsection{Dataset}

\subsubsection{GCM output}

To include as many GCMs as possible from different countries and ensure the integrity and reliability of GCM outputs, we selected GCMs recommended by the IPCC (Table 1). The climate elements included 15 meteorological variables, i.e., average temperature, relative humidity, longitudinal and latitudinal wind speeds, geopotential heights at the 500, 700 and $850 \mathrm{hPa}$ levels, and two surface climate elements (temperature and precipitation). The time scale was one month. All data were from the IPCC data center. Details of the GCMs are on the website http://ipcc-ddc.cru.uea.ac.uk. All GCM output data were normalized to $2.5^{\circ} \times 2.5^{\circ}$ by interpolation. Data series were from the period 1950 to 1999/2000.

Table 1. Information on GCMs

\begin{tabular}{|c|c|c|c|c|c|}
\hline GCMs & Abbreviation & $\begin{array}{l}\text { Developing research } \\
\text { institute }\end{array}$ & Country & Resolution & $\begin{array}{l}\text { Study } \\
\text { period }\end{array}$ \\
\hline BCCR:BCM20 & BCCR & $\begin{array}{l}\text { Bjerknes Centre for } \\
\text { Climate Research }\end{array}$ & Norway & $1.9^{\circ} \times 1.9^{\circ}$ & $\begin{array}{c}1961- \\
2000\end{array}$ \\
\hline PCM & PCM & $\begin{array}{l}\text { National Center for } \\
\text { Atmospheric Research }\end{array}$ & $\begin{array}{l}\text { United } \\
\text { States }\end{array}$ & $2.8^{\circ} \times 2.8^{\circ}$ & $\begin{array}{c}1961- \\
1999\end{array}$ \\
\hline CCSM3 & CCSM3 & $\begin{array}{l}\text { National Center for } \\
\text { Atmospheric Research }\end{array}$ & $\begin{array}{l}\text { United } \\
\text { States }\end{array}$ & $1.4^{\circ} \times 1.4^{\circ}$ & $\begin{array}{l}1961- \\
2000\end{array}$ \\
\hline CGCM2.3.2 & MRI & $\begin{array}{l}\text { Meteorological Research } \\
\text { Institute }\end{array}$ & Japan & $2.8^{\circ} \times 2.8^{\circ}$ & $\begin{array}{l}1961- \\
2000\end{array}$ \\
\hline CGCM3.1_T47 & CGCM47 & Canadian Centre for & & $2.8^{\circ} \times 2.8^{\circ}$ & \\
\hline CGCM3.1_T63 & CGCM63 & $\begin{array}{c}\text { Climate Modelling and } \\
\text { Analysis }\end{array}$ & Canada & $1.9^{\circ} \times 1.9^{\circ}$ & $\begin{array}{l}1901- \\
2000\end{array}$ \\
\hline CNRM:CM3 & CNRM & $\begin{array}{l}\text { National Centre for } \\
\text { Meteorological Research }\end{array}$ & France & $1.9^{\circ} \times 1.9^{\circ}$ & $\begin{array}{l}1961- \\
1999\end{array}$ \\
\hline CSIRO:MK30 & CSIRO30 & Atmosphere Research, & & $1.9^{\circ} \times 1.9^{\circ}$ & \\
\hline CSIRO:MK35 & CSIRO35 & $\begin{array}{c}\text { Commonwealth Scientific } \\
\text { and Industrial Research } \\
\text { Organization }\end{array}$ & Australia & $1.9^{\circ} \times 1.9^{\circ}$ & $\begin{array}{l}1961- \\
2000\end{array}$ \\
\hline ECHAM4 & ECHAM4 & $\begin{array}{c}\text { Meteorological Research } \\
\text { Center }\end{array}$ & & $2.8^{\circ} \times 2.8^{\circ}$ & $\begin{array}{c}1961- \\
2000\end{array}$ \\
\hline ECHAM5 & ECHAM5 & $\begin{array}{c}\text { Max Planck Institute für } \\
\text { Meteorologie }\end{array}$ & Germany & $1.9^{\circ} \times 1.9^{\circ}$ & $\begin{array}{l}1961- \\
2000\end{array}$ \\
\hline FGOALS:g10 & FGOALS & $\begin{array}{c}\text { State Key Laboratory of } \\
\text { Numerical Modeling for } \\
\text { Atmospheric Sciences and } \\
\text { Geophysical Fluid } \\
\text { Dynamics (LASG) / } \\
\text { Institute of Atmospheric } \\
\text { Physics }\end{array}$ & China & $2.8^{\circ} \times 2.8^{\circ}$ & $\begin{array}{c}1961- \\
1999\end{array}$ \\
\hline GFDL:CM20 & GFDL20 & U.S. Department of & & $2.0^{\circ} \times 2.5^{\circ}$ & \\
\hline GFDL:CM21 & GFDL21 & $\begin{array}{c}\text { Commerce / National } \\
\text { Oceanic and Atmospheric } \\
\text { Administration / }\end{array}$ & $\begin{array}{l}\text { United } \\
\text { States }\end{array}$ & $2.0^{\circ} \times 2.5^{\circ}$ & $\begin{array}{c}1961- \\
2000\end{array}$ \\
\hline
\end{tabular}




\begin{tabular}{|c|c|c|c|c|c|}
\hline & & $\begin{array}{c}\text { Geophysical Fluid } \\
\text { Dynamics Laboratory }\end{array}$ & & & \multirow{4}{*}{$\begin{array}{l}1961- \\
2000\end{array}$} \\
\hline GISS:AOM & GISSAOM & National Aeronautics and & \multirow{3}{*}{$\begin{array}{l}\text { United } \\
\text { States }\end{array}$} & $3^{\circ} \times 4^{\circ}$ & \\
\hline GISS:EH & GISSEH & $\begin{array}{l}\text { Space Administration } \\
\text { (NASA) / Goddard }\end{array}$ & & $4^{\circ} \times 5^{\circ}$ & \\
\hline GISS:ER & GISSER & $\begin{array}{l}\text { Institute for Space Studies } \\
\text { (GISS) }\end{array}$ & & $4^{\circ} \times 5^{\circ}$ & \\
\hline HadCM3 & HadCM3 & Met Office Hadley Centre & United & $2.5^{\circ} \times 3.75^{\circ}$ & 1961- \\
\hline HadGEM1 & HadGEM1 & $\begin{array}{c}\text { for Climate Science and } \\
\text { Services }\end{array}$ & Kingdom & $1.3^{\circ} \times 1.9^{\circ}$ & 1999 \\
\hline INM:CM30 & INM & $\begin{array}{c}\text { College of Computational } \\
\text { Mathematics }\end{array}$ & Russia & $4^{\circ} \times 5^{\circ}$ & $\begin{array}{c}1961- \\
2000\end{array}$ \\
\hline IPSL:CM4 & IPSL & $\begin{array}{l}\text { Pierre-Simon marquis de } \\
\text { Laplace }\end{array}$ & France & $2.5^{\circ} \times 3.75^{\circ}$ & $\begin{array}{l}1961- \\
2000\end{array}$ \\
\hline MIROC3.2_hires & MIROC-h & Climate System Research & & $1.1^{\circ} \times 1.1^{\circ}$ & \\
\hline MIROC3.2_medres & MIROC-m & $\begin{array}{l}\text { Center, Tokyo University; } \\
\text { National Environment } \\
\text { Research Institute; } \\
\text { Frontier Research Center } \\
\text { for Global Change } \\
\text { (JAMSTEC) }\end{array}$ & Japan & $2.8^{\circ} \times 2.8^{\circ}$ & $\begin{array}{l}1961- \\
2000\end{array}$ \\
\hline
\end{tabular}

\subsubsection{ERA-40/NCEP reanalysis data}

ERA-40 and NCEP reanalysis data were taken as the measured data of the meteorological variables to assess the suitability of GCM outputs.

\subsubsection{Surface observational data}

Gridded data of monthly average temperature and monthly precipitation from the China Meteorological Administration (http://ncc.cma.gov.cn) were used, which were resampled to $2.5^{\circ} \times$ $2.5^{\circ}$ grids. Then, the data were used to assess GCM surface output results.

\section{Results and discussion}

\subsection{GCM suitability assessment results}

\subsubsection{The Yangtze River basin}

The Yangtze is the longest river in China $(6393 \mathrm{~km})$ and has a total basin area of 1.8 million $\mathrm{km}^{2}$, accounting for $18.75 \%$ of the national area. Mountains and hills take up to $84.7 \%$ of the entire basin area, plains $11.3 \%$, and rivers and lakes $4 \%$. There is a mild and humid climate, with abundant rainfall and average annual precipitation $1100 \mathrm{~mm}$. The average annual water volume flowing into the sea reaches 960 billion $\mathrm{m}^{3}$. The Yangtze River basin supports water and energy resources for the most populated area in China. It is very important to study the response of the water cycle in the basin to climate change for the development of water resources and national economy. Figure 1 shows the GCM grids used in this study. 


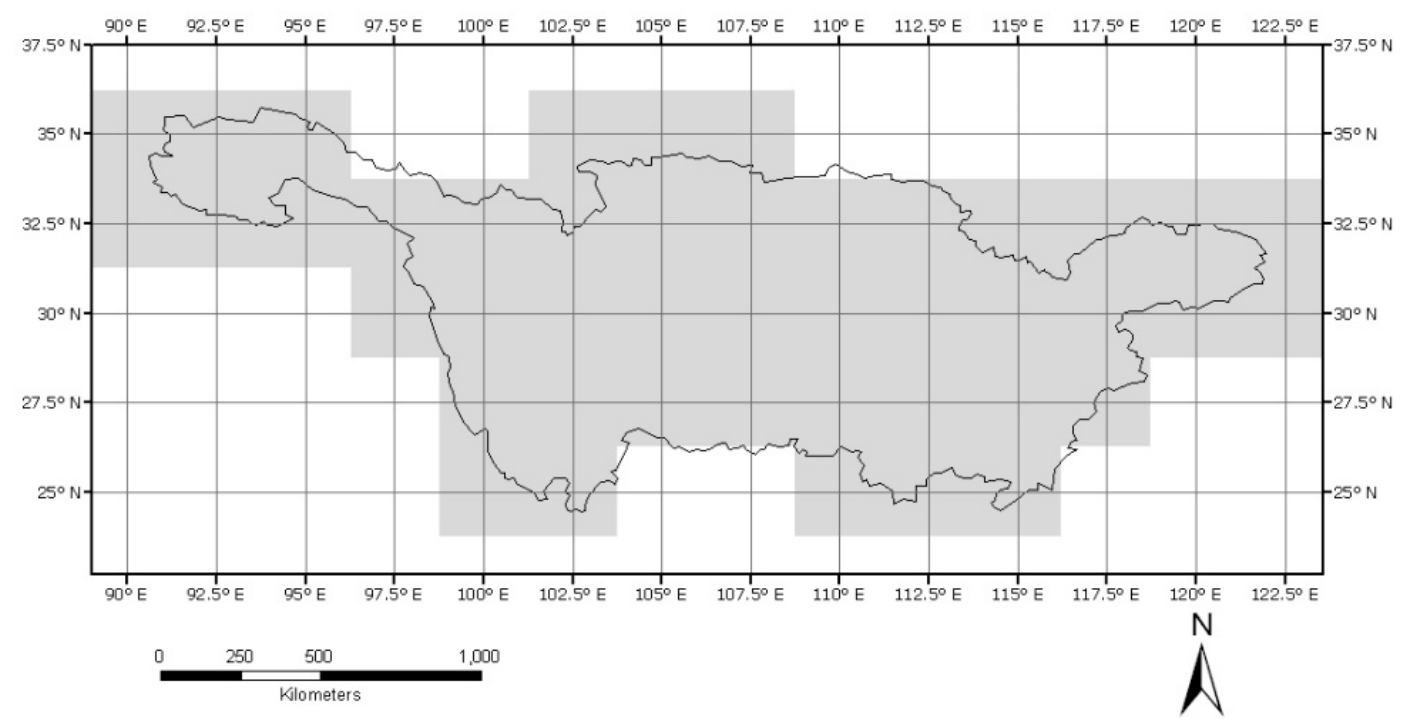

Figure 1. Grids of Yangtze River basin

Comprehensive assessment results indicate that FGOALS, ECHAM4, ECHAM5, HadCM3, HadGEM1 and MRI had better performance in the Yangtze River basin than other GCMs (Figure 2). Zhang et al. [42] investigated spatiotemporal and circulation characteristics of the water vapor budget in the basin, and emphasized the influence of latitudinal water vapor transport originating from the Bay of Bengal on basin relative humidity. The simulation results of longitudinal and latitudinal wind speed strongly affected the spatiotemporal distribution of basin relative humidity. In the present study, four GCMs that effectively simulated relative humidity (ECHAM4, FGOALS, HadCM3 and HadGEM1) also showed good simulation of longitudinal and latitudinal wind speeds, consistent with previous studies. Temperature simulation results were better than other variables (including relative humidity), also demonstrated in previous studies. Xu et al. [43] simulated climate change in East Asia based on five climate models, including temperature, precipitation, diurnal range and water vapor data. Their assessment results indicated that ECHAM4 and HadCM2 had best performance in China. In the present study, these two models also demonstrated promising outcomes. However, during assessment of GCM suitability in the Murray-Darling Basin of Australia, Maxino et al. [44] obtained larger GCM-computed values of temperature than measured values for most GCMs. In contrast, in an assessment of GCM suitability in the Yellow River basin by Cao et al. [45], the computed temperature was consistently cooler. In the present study, the computed temperature was warmer in most GCMs than measured. This might have resulted from a large difference of regional climate and circulation characteristics in the basins, as well as different GCM responses to climate characteristic variation. Therefore, it is necessary to assess GCM suitability across different basins. 


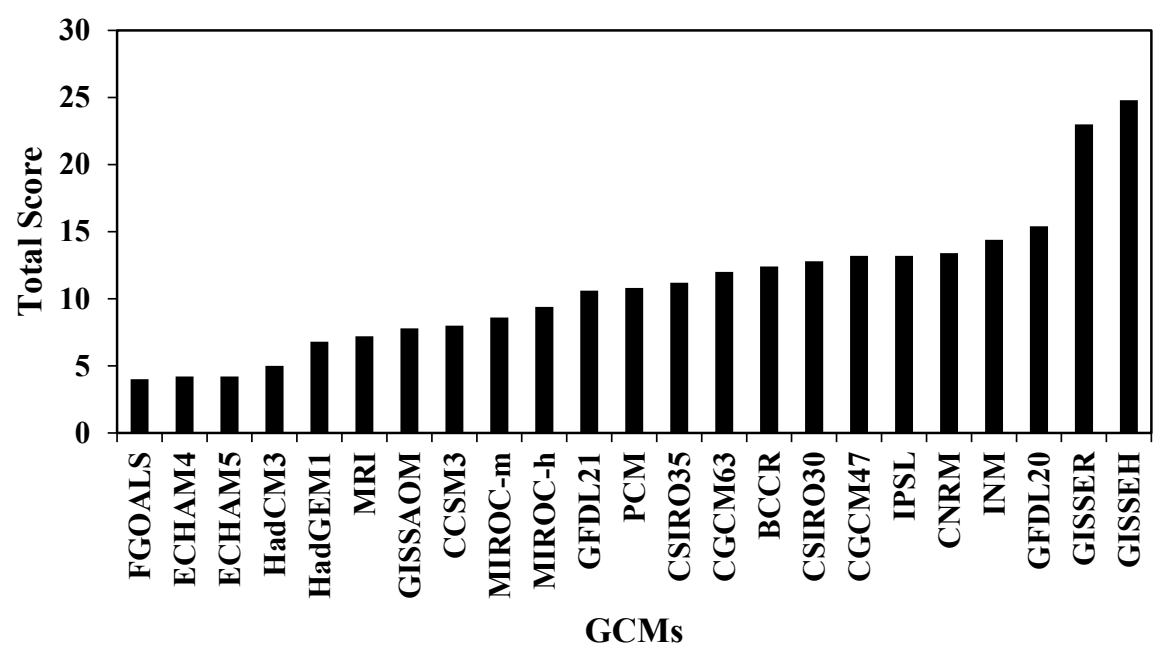

Figure 2. Comprehensive scoring of GCMs in Yangtze River basin

Specifically, we chose the Taihu basin to investigate the influences of climate change on the water cycle in the Yangtze River basin and evaluate GCM suitability. This basin is in the southern Yangtze River Delta. Associated administrative regions include southern Jiangsu, Jiaxing, Huzhou, part of Hangzhou in Zhejiang, and most of Shanghai, one of the most economically developed and populated regions in China. The basin water cycle is extremely sensitive to climate change.

Figure 3 shows RS scores in increasing order. The lower the score is, the better the GCM performance for climate simulation is. Thus, it is seen that the BCCR model had the best performance overall. Therefore, it was used to assess the impacts of climate change. The simulated daily climate data were exported to the A1B scenario including two components, the current period (1961-2000, 20c3m scenario) and future periods (2046-2065 and 2081-2100). A1B is characterized by balanced economic development and greenhouse gas emissions, and is therefore suitable for future planning of coordinated water-economic-environment development in the Taihu basin.

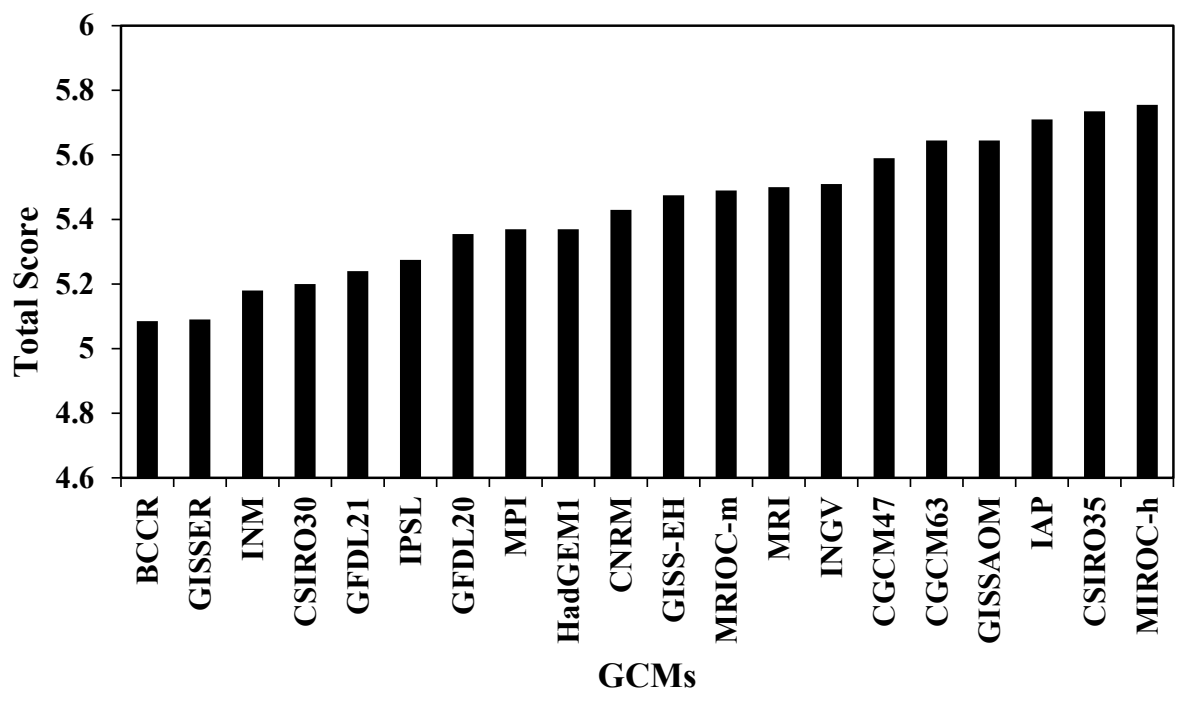

Figure 3. Comprehensive scoring of GCMs in Taihu basin

\subsubsection{The Yellow River basin}

We selected 25 grids of GCM data over the Yellow River basin (Figure 4). All GCM data were interpolated to a resolution of $2.5^{\circ} \times 2.5^{\circ}$. The comprehensive results showed that the top ten climate 
models were the MRI, HadGEM1, INM, CSIRO30, MIROC-M, HadCM3, BCCR, GFDL20, CGCM47, and GFDL21 (Figure 5).

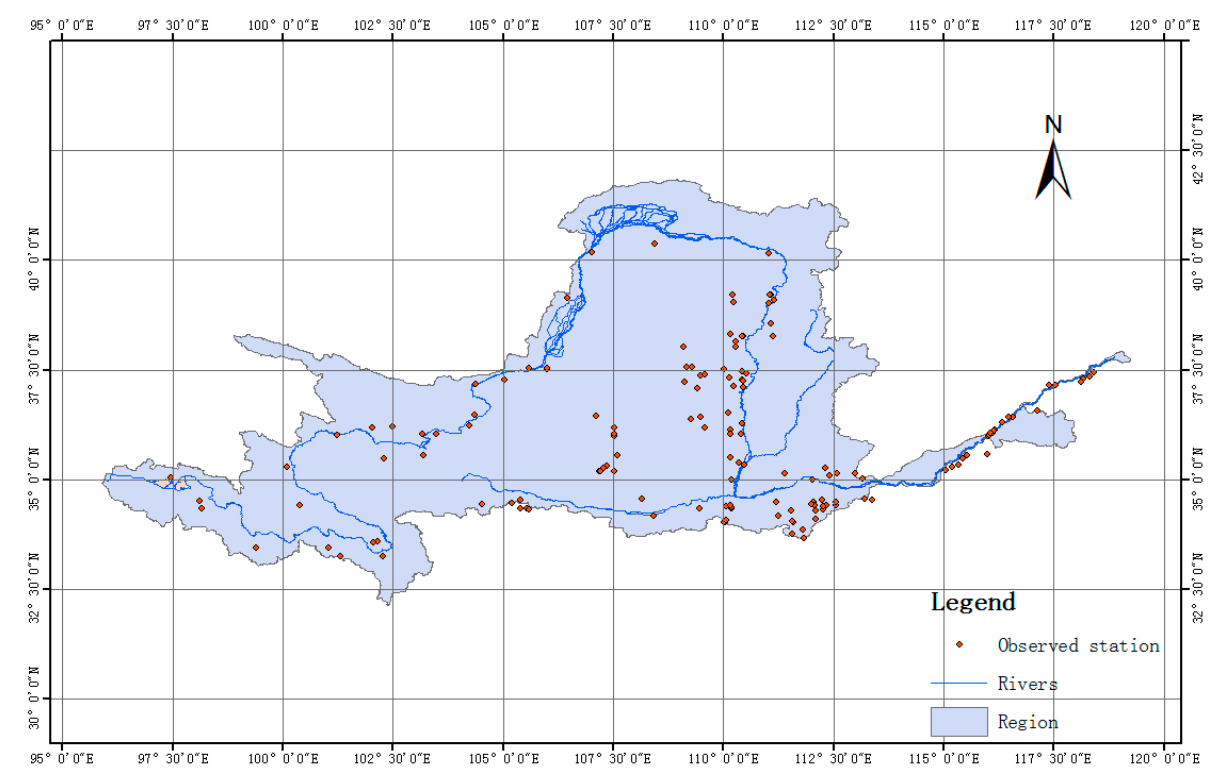

Figure 4. Grids of Yellow River basin

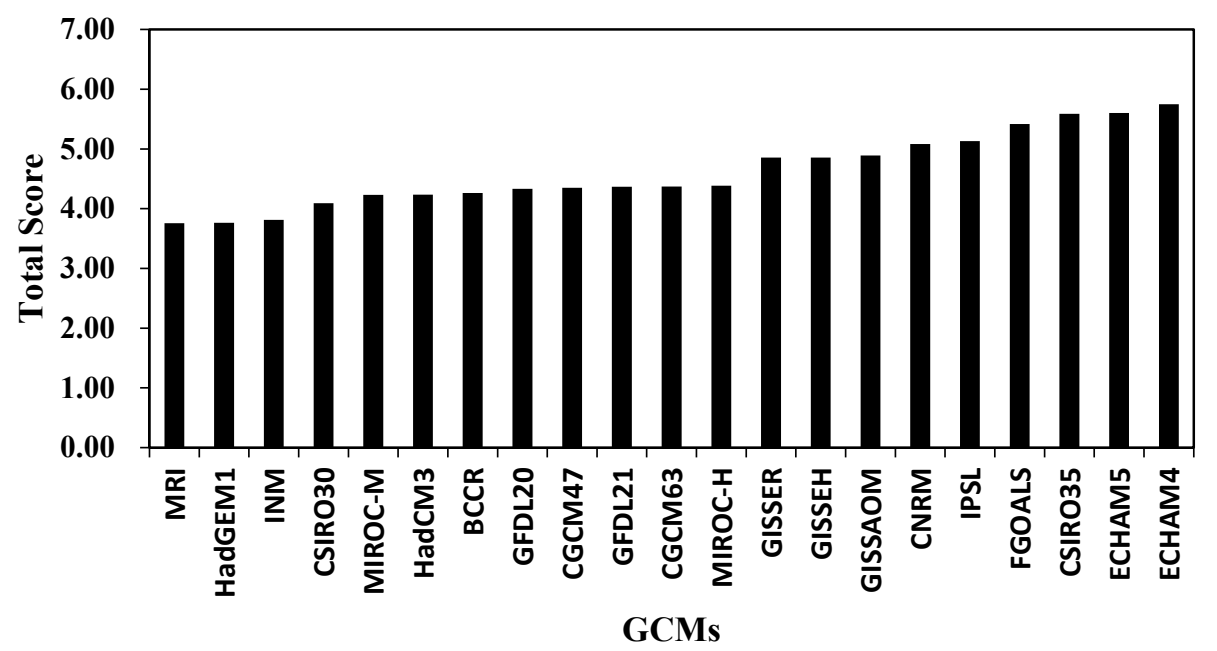

Figure 5. Comprehensive scoring of GCMs in Yellow River basin

While studying summer water vapor transport in the Asian monsoon zone and effects on precipitation in China, Zhou et al. [46] observed the important role of longitudinal and latitudinal water vapor transport by the Indian monsoon to relative humidity of the basin in China. Also, it was reported that relative humidity was to a large extent affected by the simulation performance of longitudinal and latitudinal wind speeds. In the present study, the GCMs with favorable simulation of relative humidity (MRI, HadGEM1 and GFDL20) also showed good performance in simulation of those wind speeds. This is consistent with the finds of Zhou et al. [46].

To analyze uncertainty caused by multiple GCMs and different scenarios and comprehensively consider the consistency and integrity of scenario data in different models, we compared A2 and B1 scenario data in MRI, CSIRO30 and INM, which had the best performance in the Yellow River basin. 


\subsection{Impacts of climate change on water cycle}

\subsubsection{The Yangtze River basin}

- $\quad$ Construction of future climate change scenario

In a previous study by the authors [47], we conducted a comparison of statistical downscaling models for the Taihu basin. Specifically, the SDSM and ASD model were used to construct future climate change scenarios for that basin. The results indicated that ASD optimized the selection of predictors, and the simulation results were superior to those of SDSM. Therefore, the ASD model was used herein to construct future climate change scenarios.

ASD downscaling results revealed that the variation of future precipitation was complex and substantial compared to that of future temperature. Figure 6 shows that in the two future periods (2046-2065 and 2081-2100), the majority of months showed an increasing tendency in precipitation. The increase was large in spring and summer (except August), but smaller in other months. Compared to precipitation in 1961-1990, precipitation ranged between -0.3 and $83.6 \mathrm{~mm}$ and -5.3 and $89.5 \mathrm{~mm}$ in 2046-2065 and 2081-2100, respectively. In general, precipitation in the two future periods will not change significantly. Intra-annual variation was consistent, with reduced precipitation in January, August and December, and increased precipitation in March, May and July.

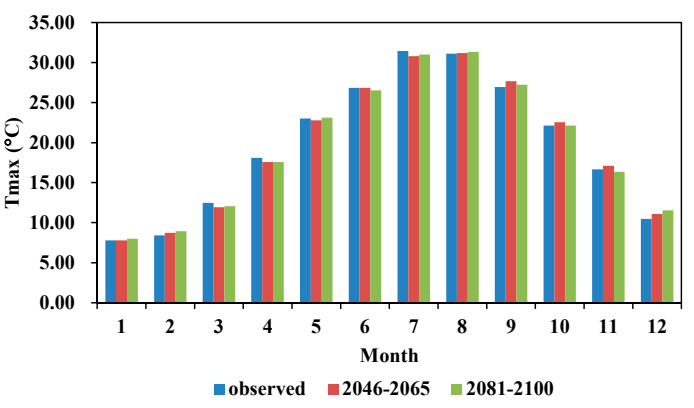

(a)

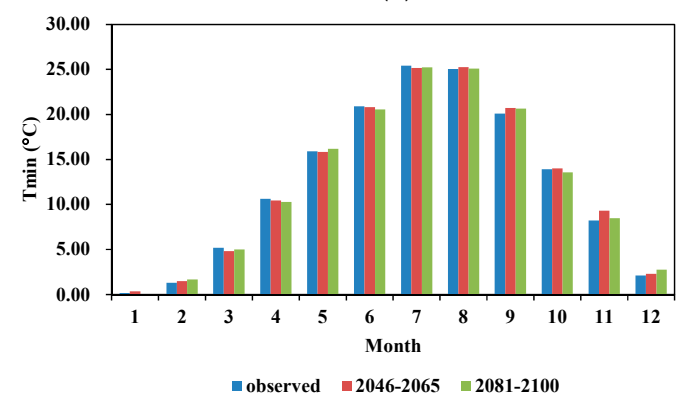

(c)

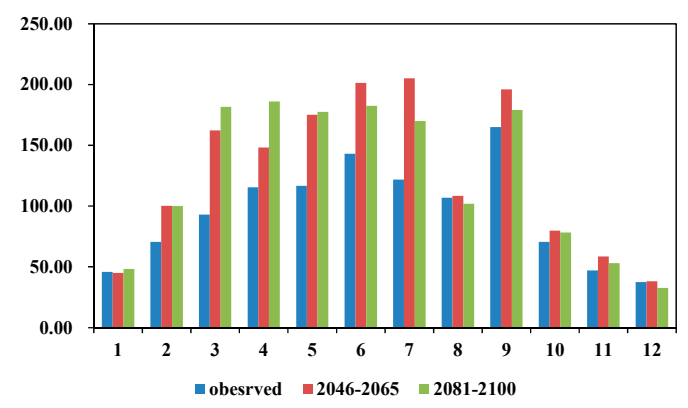

(e)

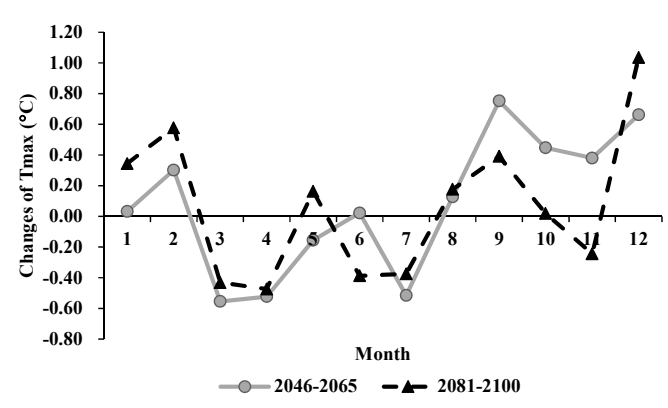

(b)

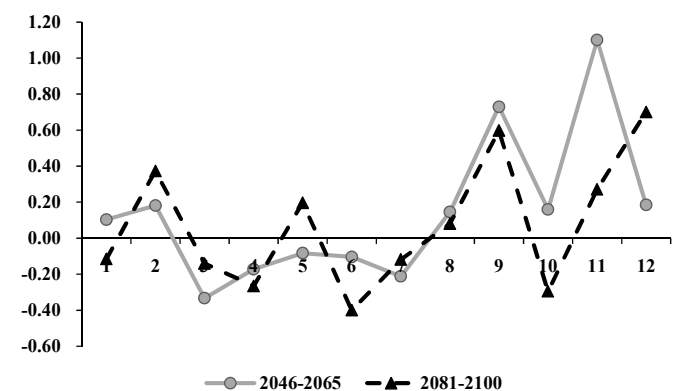

(d)

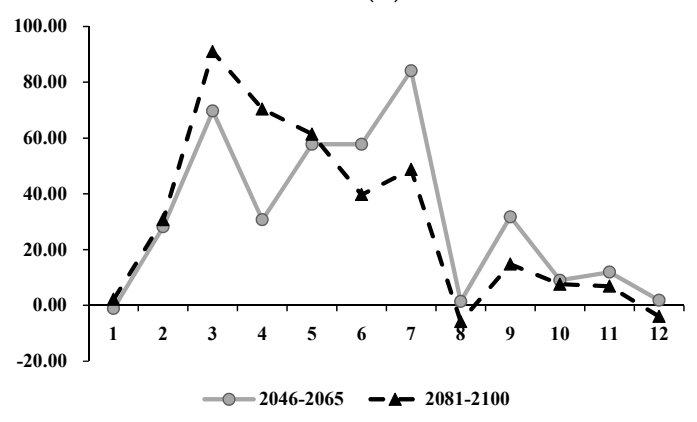

(f)

Figure 6. Daily maximum temperature $(a-b)$, minimum temperature $(c-d)$, precipitation $(e-f)$ and their variations in the Taihu basin during two future periods predicted by ASD downscaling model (a, c, and e are comparisons between three elements and their measured values; $b, d$, and $f$ are monthly changes compared to baseline period) 
- Response to climate change of water cycle

The authors successfully constructed VIC for the Taihu basin [48], which was used in the present study. For meteorological data series under the A1B scenario during the baseline period (1961-1990) generated by the ASD model, including daily precipitation, daily maximum and minimum temperatures, the Thiessen polygon method was used to interpolate the data to $5 \mathrm{~km} \times 5$ $\mathrm{km}$ grids, thereby creating climate forcing data. Based on soil and vegetation parameters of the constructed VIC model of the Taihu basin [48], the model was run on 1452 grids of the basin, exporting daily runoff depth data at every grid for the period 1961-1990.

Similarly, based on meteorological data series in the future periods (2046-2065 and 2081-2100) generated by ASD, including daily precipitation, daily maximum and daily minimum temperatures, daily runoff depth data at every grid were exported.

Figure 7 shows monthly changes of runoff depth on each grid for 2046-2065, compared to the baseline period. It is seen that in most areas of the basin, there was a decreasing tendency in monthly runoff depth in the future, of varying magnitude. Areas with large reductions of runoff depth were western Zhejiang and Zhangzhou-Jiaxing-Huzhou; the other areas showed lesser reductions. Particularly, Shanghai showed an increasing tendency during most of the year (January-April and September-December). Western Zhejiang demonstrated a slight increase in runoff depth during flood season.
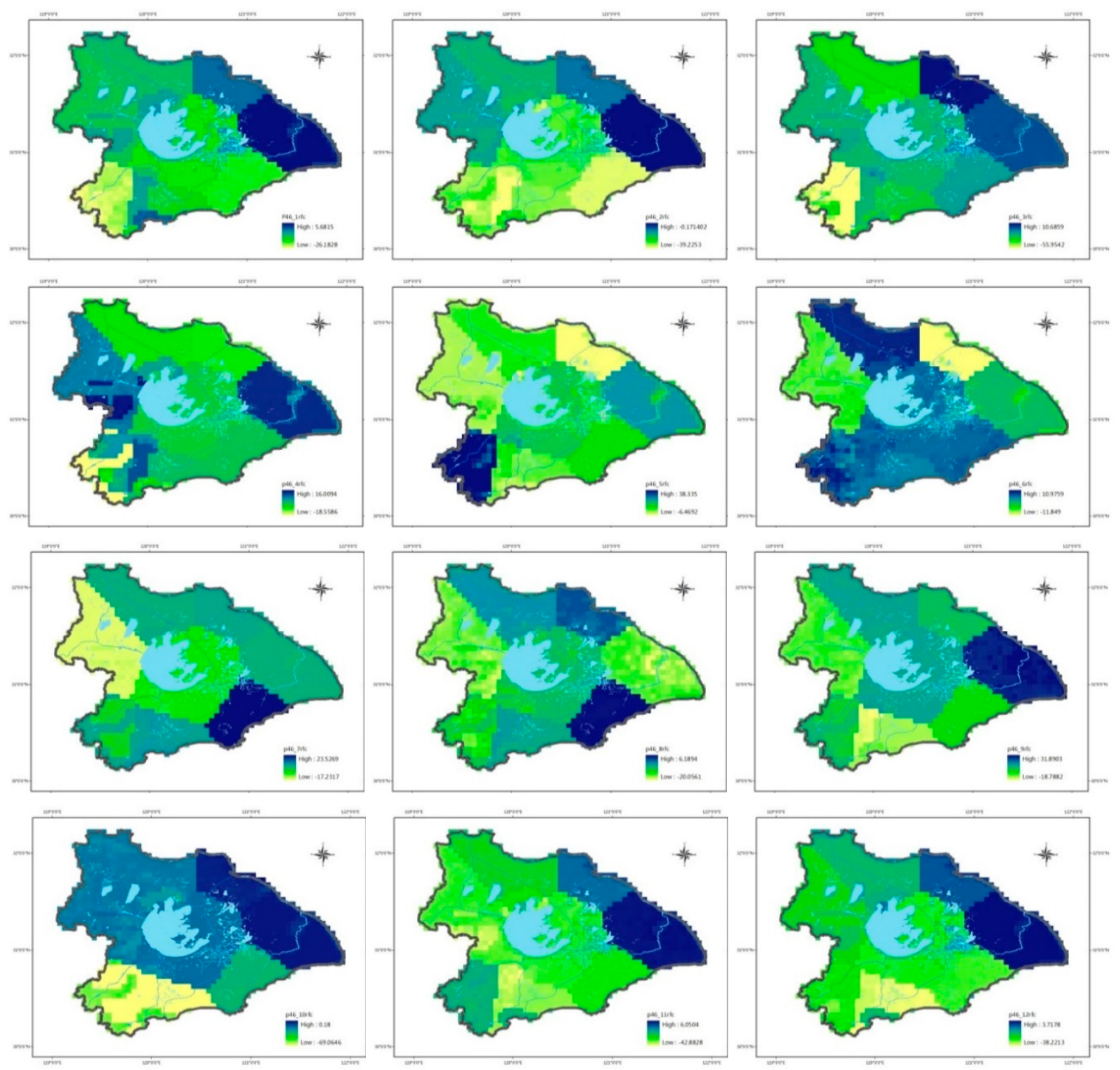

Figure 7. Spatial distribution of monthly runoff depth variation during 2046-2065 under A1B scenario 
Figure 8 shows monthly changes of runoff depth at every grid between 2081-2100 and the baseline period. It is seen that in most areas of the basin, there was a decreasing tendency of monthly runoff depth in the future, with varying magnitude. The runoff depth in the western Zhejiang area tended to decrease compared to the baseline period, but the magnitude of decrease was less than that during 2046-2065. The Yangchengdian area had the largest reduction in runoff depth during March and May, whereas the Hangzhou-Jiaxing-Huzhou area showed a relatively large reduction in winter. Similar to the earlier period of 2046-2065, there was an increasing tendency in Shanghai during most of the year (January-April and October-December).
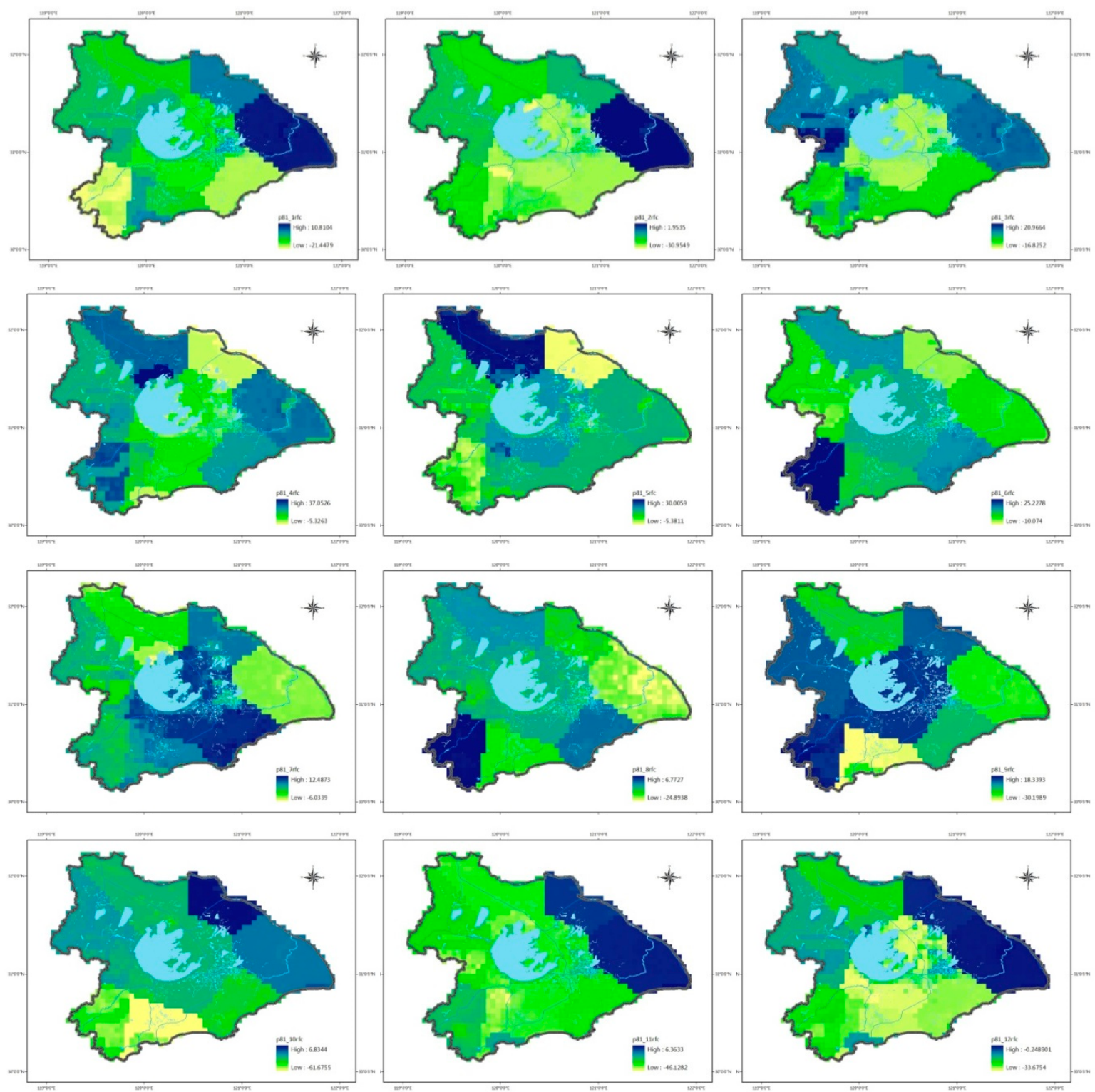

Figure 8. Spatial distribution of monthly runoff depth variation during 2081-2100 under A1B scenario

\subsubsection{The Yellow River basin}

- $\quad$ Construction of future climate change scenario

Based on results of GCM suitability assessment, output data of three GCMs (MRI, CSIRO30, and INM) in the A2 and B1 scenarios were used and underwent interpolation to form $2.5^{\circ} \times 2.5^{\circ}$ grids. The three simulation periods were the same as above. The SDSM model was used for downscaling. Twelve daily predictors were chosen, covering 25 grids in the Yellow River basin. The 
observation data contained daily precipitation, average temperature, and maximum and minimum temperatures at 79 stations in the basin from 1961 to 1990.

Figure 9 displays the simulation results of monthly maximum and minimum temperatures from six conditions (three GCMs, each using the A2 and B1 scenarios). It is seen that both monthly maximum and minimum temperatures had increasing tendencies in most months of the year for all six conditions.

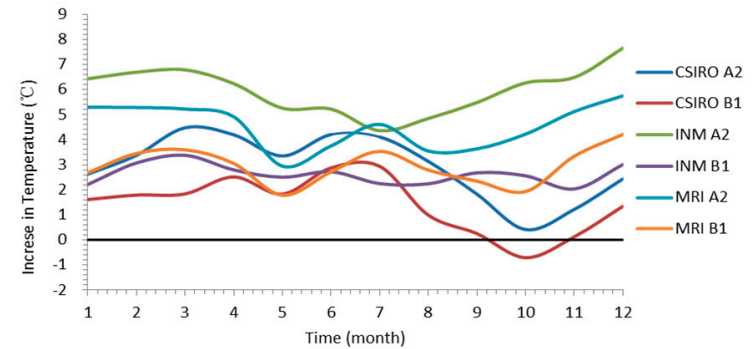

(a)

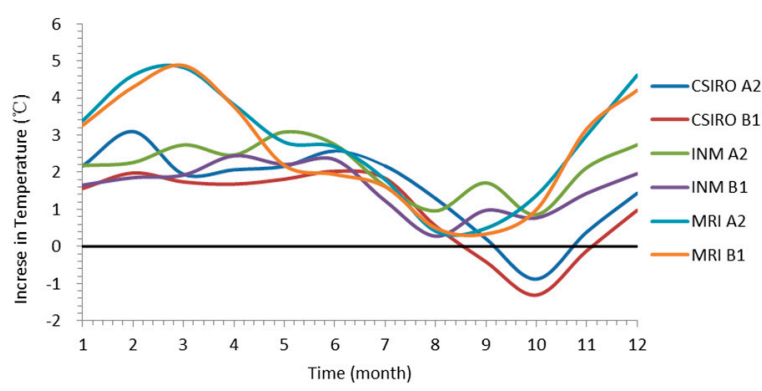

(c)

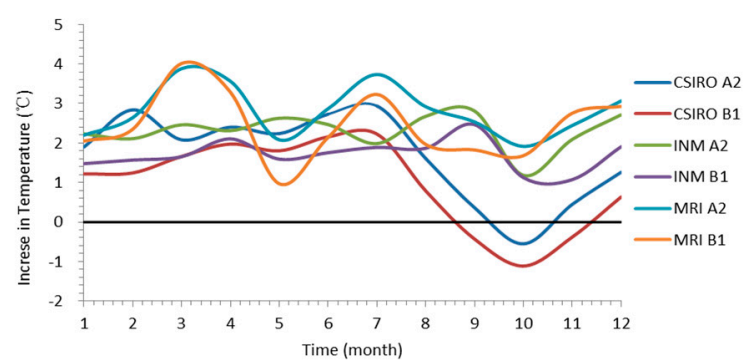

(b)

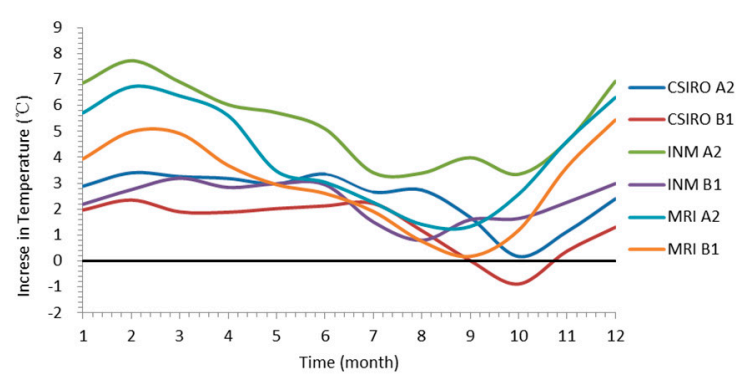

(d)

Figure 9. Changes of simulated monthly maximum ( $a$ and $b$ ) and minimum (c and d) temperature under scenarios A2 and B1 during the period of 2046-2065 and 2081-2100 respectively

The variation of precipitation was substantially different between conditions (Figure 10). Overall, the CSIRO30 model showed a minimal reduction (monthly variation $<25 \%$ ) in precipitation, whereas MRI produced the greatest precipitation increase.

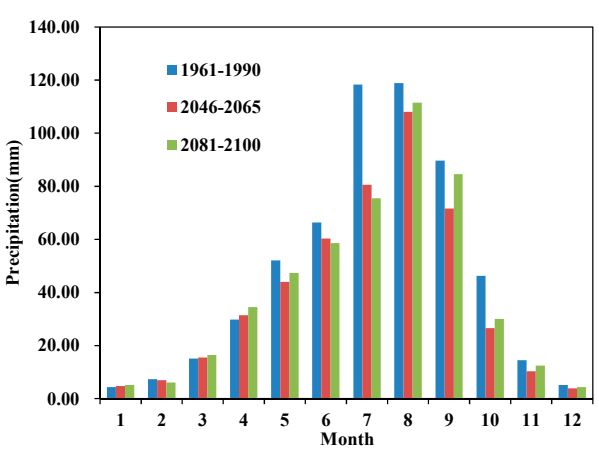

(a)

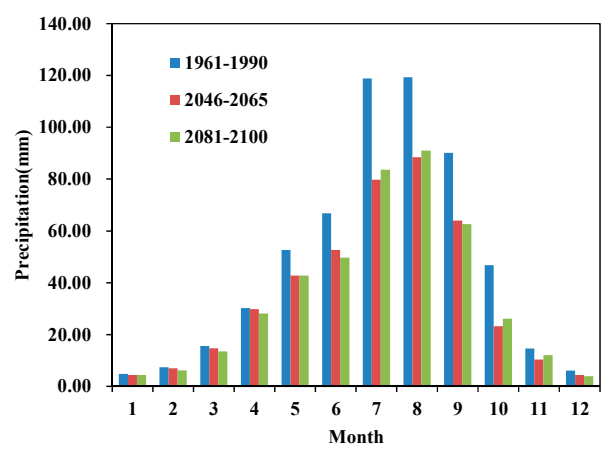

(b) 


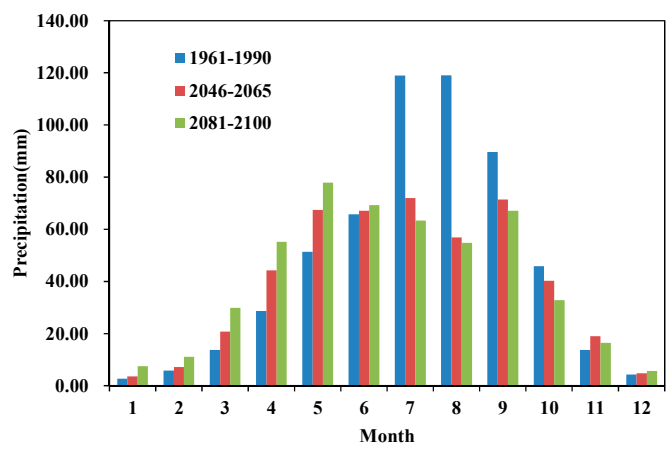

(c)

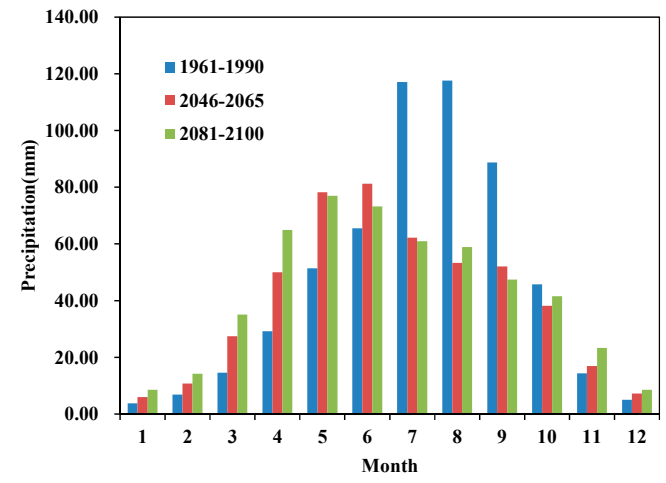

(e)

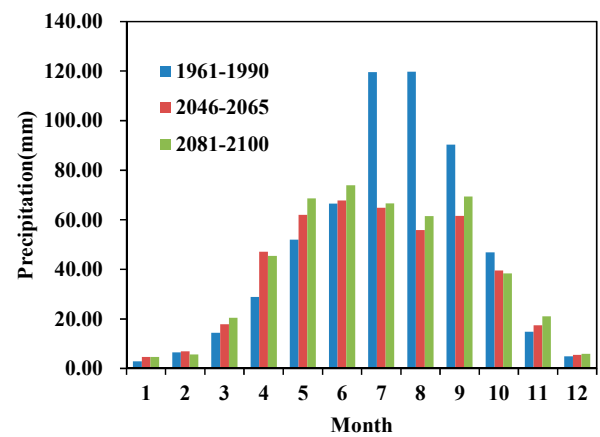

(d)

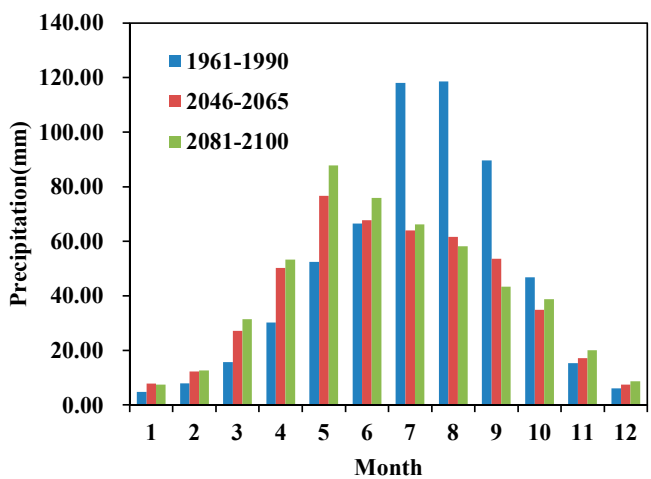

(f)

Figure 10. Simulation results of precipitation from three GCMs (a-b: CSIRO30; $c-d$ : INM; e-f: MRI) under various scenarios (a, c, and e: A2; b, d and f: B1)

- Response to climate change of water cycle

(1) Construction of distributed hydrological model

The upper reaches of the Yellow River are on the Qinghai-Tibetan Plateau, bordering the Bayan Har Mountains in the south, Qaidam Basin in the north, Kunlun mountains in the west, and Loess Plateau in the east. The geomorphology is alpine grassland. The segment above Lanzhou (hereafter referred to as the upper reaches) has a total length of $2119 \mathrm{~km}$ and catchment area of $224,749 \mathrm{~km}^{2}$, accounting for $28 \%$ of that in the entire basin. Figure 11 shows the location of the river basin. 


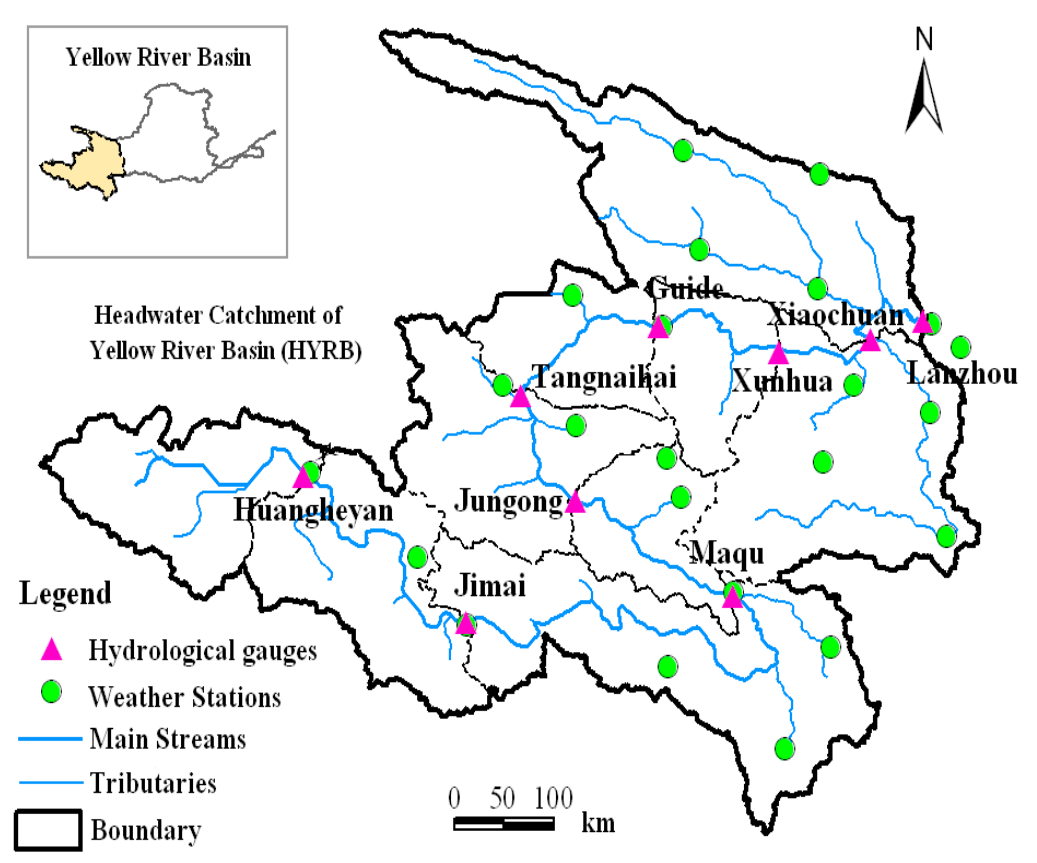

Figure 11. Upper reaches of Yellow River

The SWAT model with the built-in parameter sensitivity analysis module was calibrated and validated during 1971-1985 and 1986-2000, respectively. Figure 12 shows a comparison between discharge simulation and measured values at the Lanzhou hydrological station during the calibration and validation periods. In general, model indexes were satisfactory. The Nash-Sutcliffe efficiency and determination coefficients were 0.667 and 0.773 in the calibration period, and 0.626 and 0.709 in the validation period. Hence, the model showed good performance in simulating water balance in the basin.

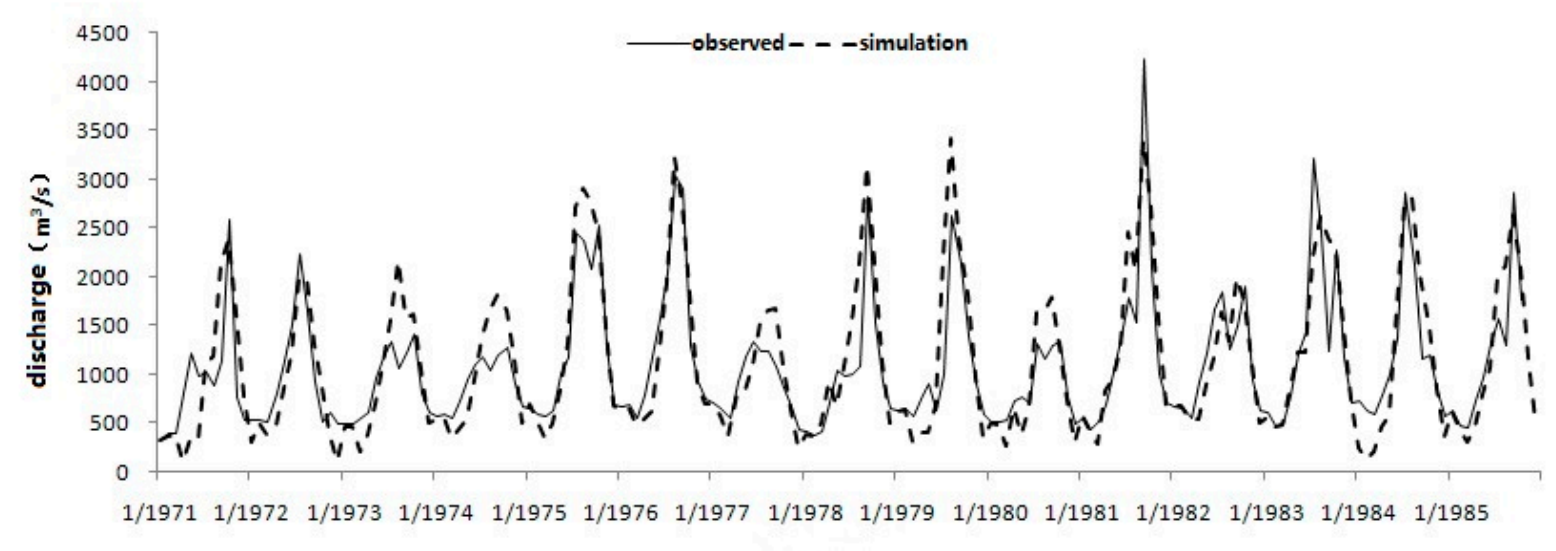

Month

(a) 


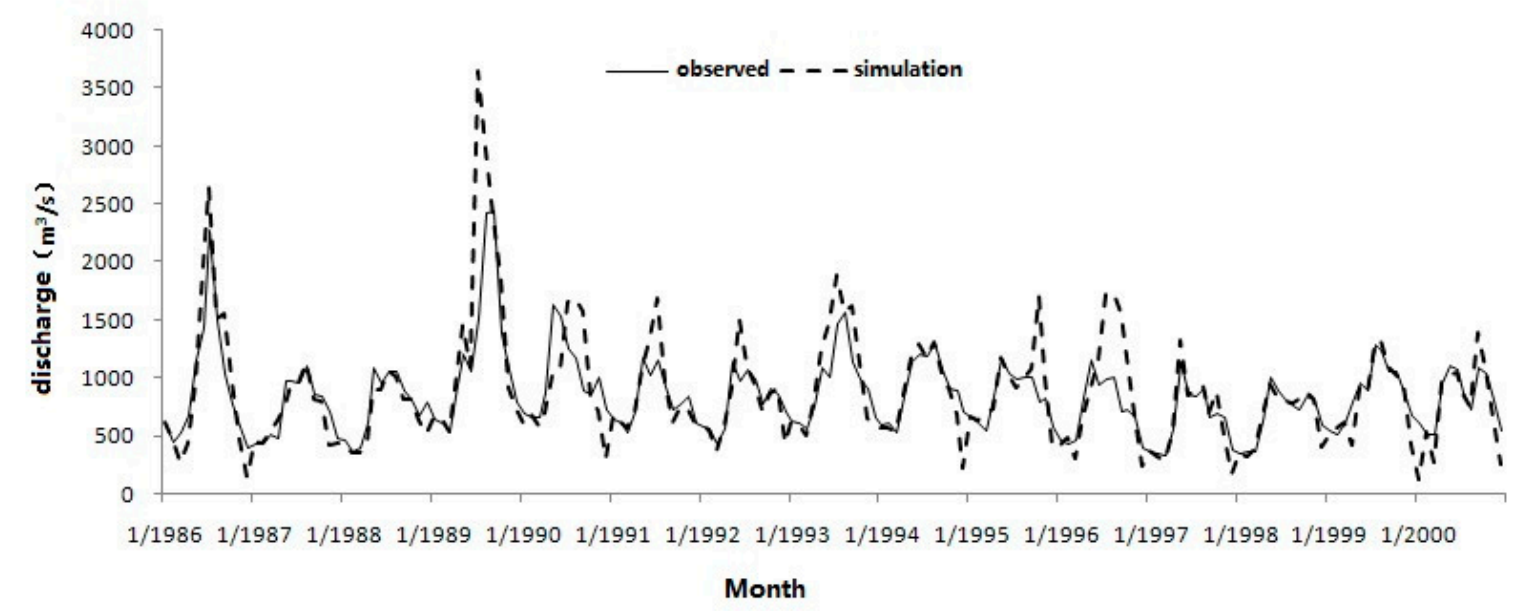

(b)

Figure 12. Fitted curve of monthly discharge simulation to measured values at Lanzhou hydrological station (a: calibration period; b: validation period)

(2) Response of runoff to future climate change in upper Yellow River basin

Figures 13-15 present the spatial distribution of mean annual runoff depth during 2046-2065 and 2081-2100 compared to the baseline period, for every sub-basin and downscaling scenarios of the three GCMs. The runoff depth variation of the CSIRO model was -35.8 to $43 \mathrm{~mm}$. In most areas, the variation was between -5 and $-20 \mathrm{~mm}$. Overall, the tendency of basin runoff was consistent between different scenario combinations, with runoff decreases in the majority of sub-basins. The area of runoff depth reduction was less under the B1 scenario than that under the A2 scenario. Runoff depth decreased greatly in the Hongyuan, Jiuzhi and Ruoergai areas, generally between -35 and $-21 \mathrm{~mm}$. In general, in the downscaling scenario of the CSIRO model, basin runoff depth tended to decrease in most sub-basins.

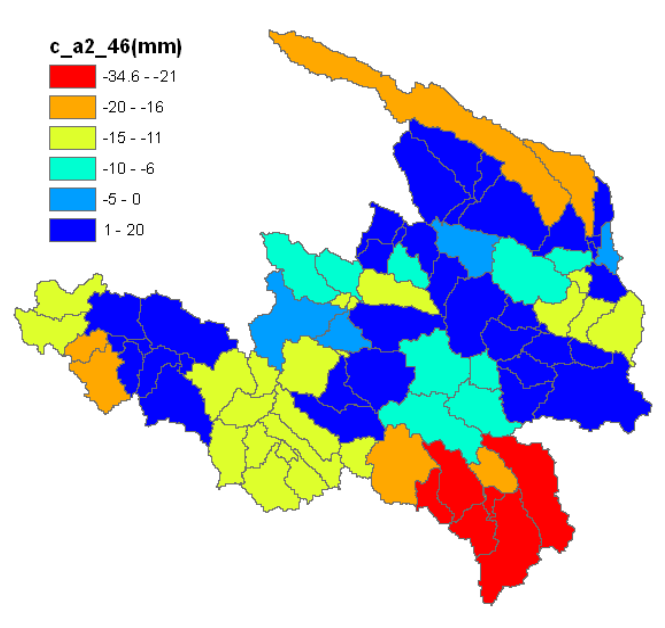

(a)

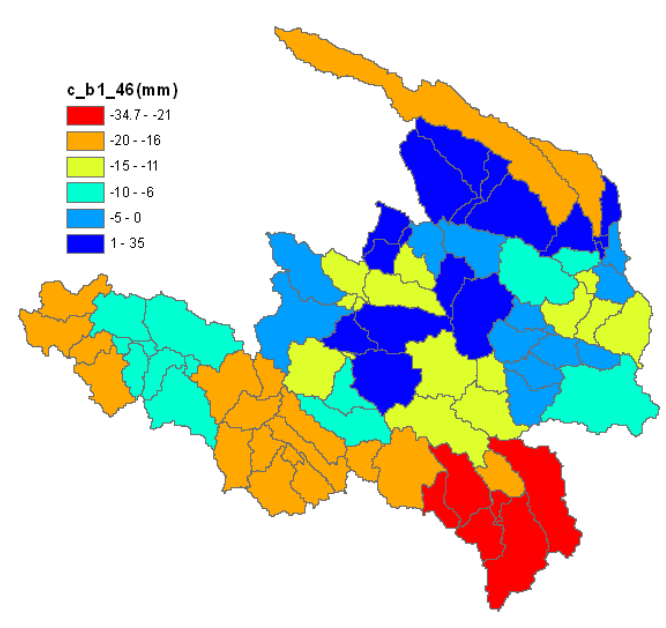

(b) 


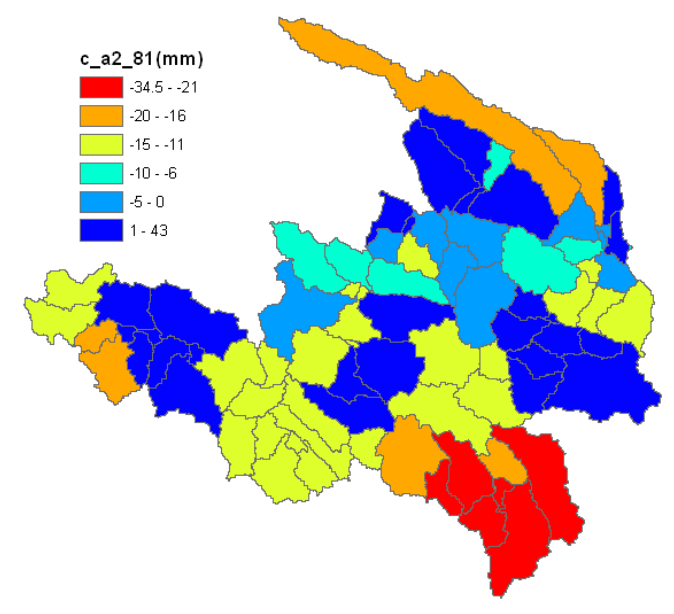

(c)

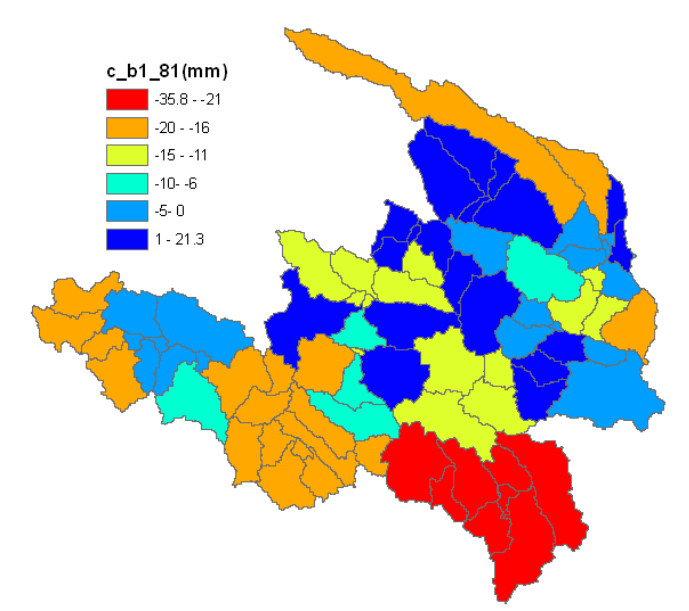

(d)

Figure13. CSIRO-estimated spatial distribution of mean annual runoff depth in sub-basins for 20462065 ( $a$ and b) and 2081-2100 (c and d) compared to baseline period

For various scenario combinations of the INM model, changes of runoff depth were between -33.9 and $61 \mathrm{~mm}$, with decreases in most sub-basins. The tendency of runoff depth with different scenario combinations was relatively consistent, showing decreasing tendencies (in excess of $20 \mathrm{~mm}$ ) in southern sub-basins, and mixed increases and decreases in northern sub-basins. under the A2 emission scenario of INM, the area of sub-basins with reduced runoff during 2081-2100 was larger than that in 2046-2065. Under the B1 scenario, the area was smaller in 2081-2100. The Hongyuan, Jiuzhi, and Ruoergai areas had large reductions in runoff depth, between -31 and $-21 \mathrm{~mm}$.

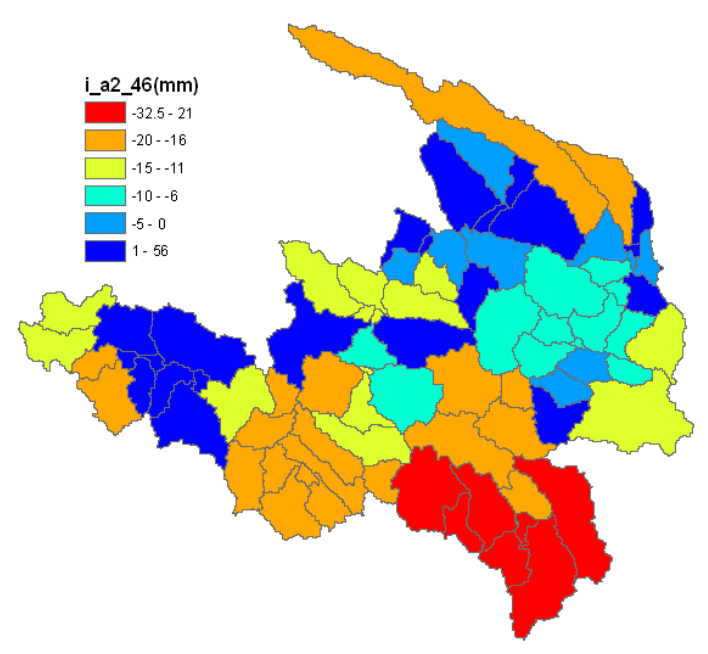

(a)

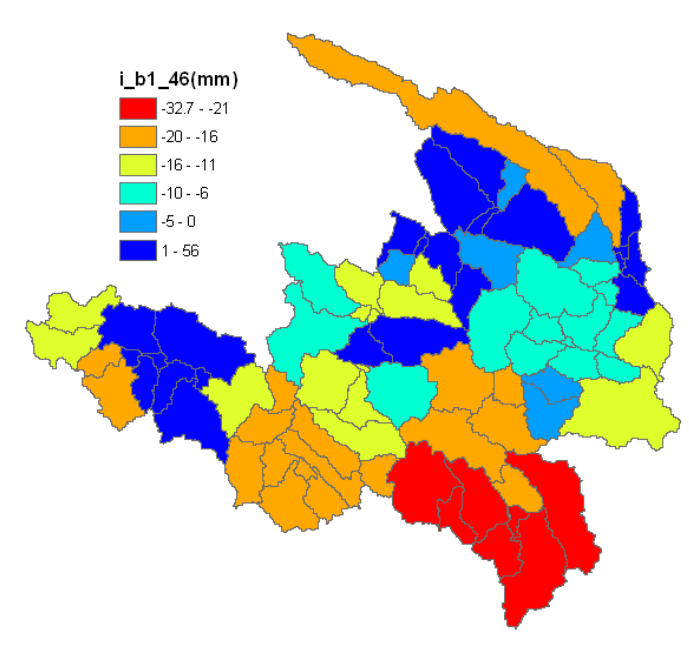

(b) 


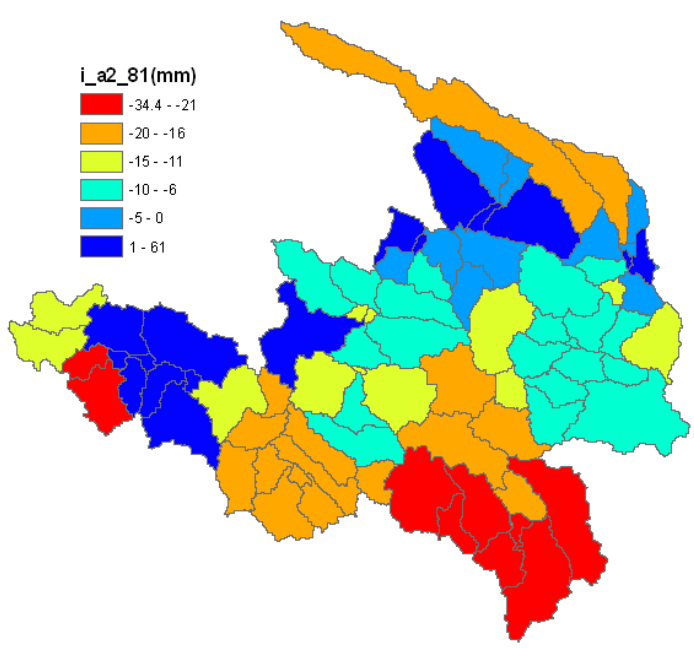

(c)

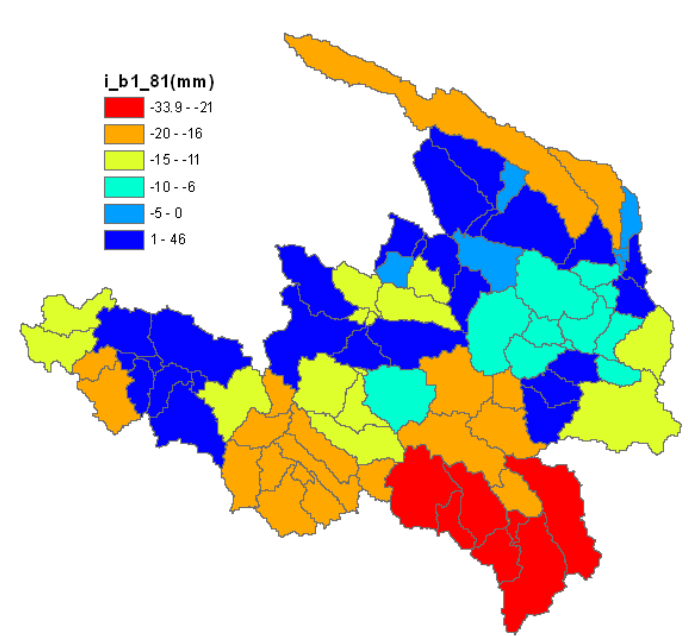

(d)

Figure 14. INM-estimated spatial distribution of mean annual runoff depth in sub-basins for 20462065 ( $a$ and b) and 2081-2100 (c and d) compared to baseline period

For different scenario combinations of the MRI model, runoff depth was between -32.9 and 69 $\mathrm{mm}$, with over half the area of sub-basins showing a decreasing tendency in average runoff depth. In the period 2046-2065, the area of sub-basins with increasing runoff under the A2 scenario was larger than that under the B1 scenario, as was the area with reductions of 16-20 mm. For 2081-2100, the area of sub-basins with increasing runoff under the B1 scenario was larger than that under the A2 scenario, as was the area with reductions of $16-20 \mathrm{~mm}$. The MRI model produced a decreasing tendency in runoff depth over half the basin area. In addition, that depth decreased greatly in Hongyuan, Jiuzhi and Ruoergai, generally between -35 and $-21 \mathrm{~mm}$.

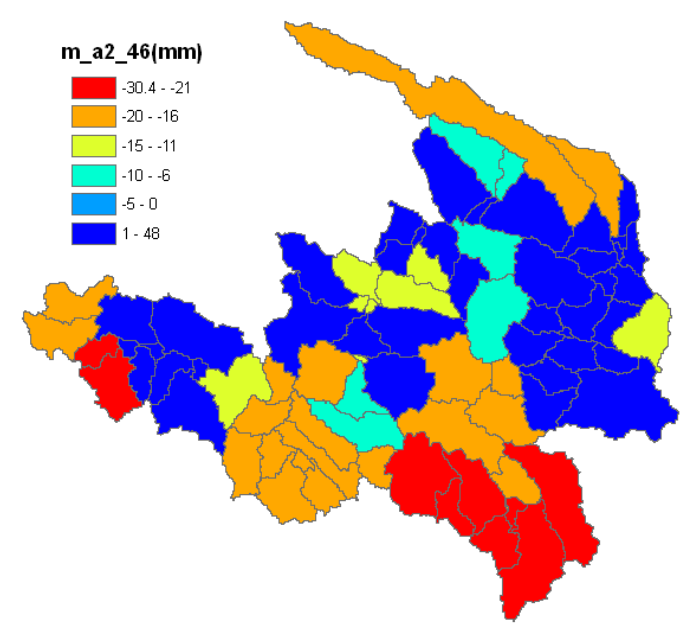

(a)

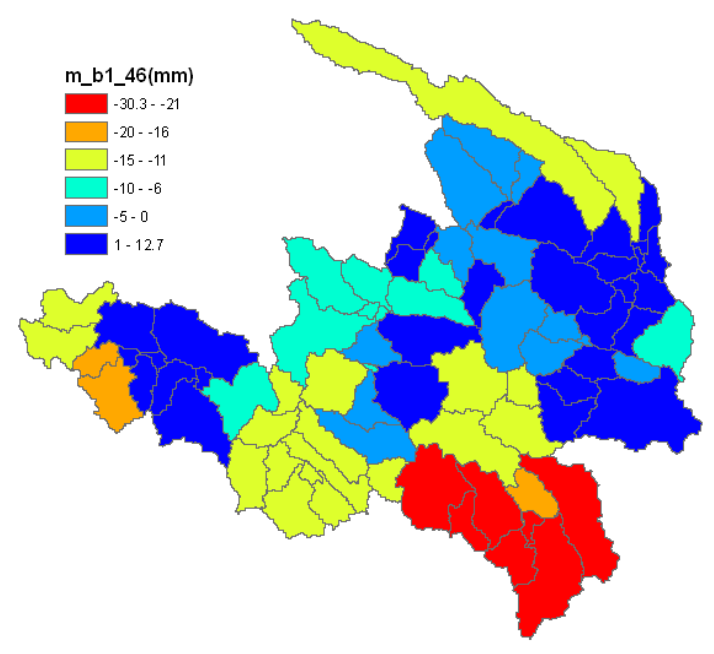

(b) 


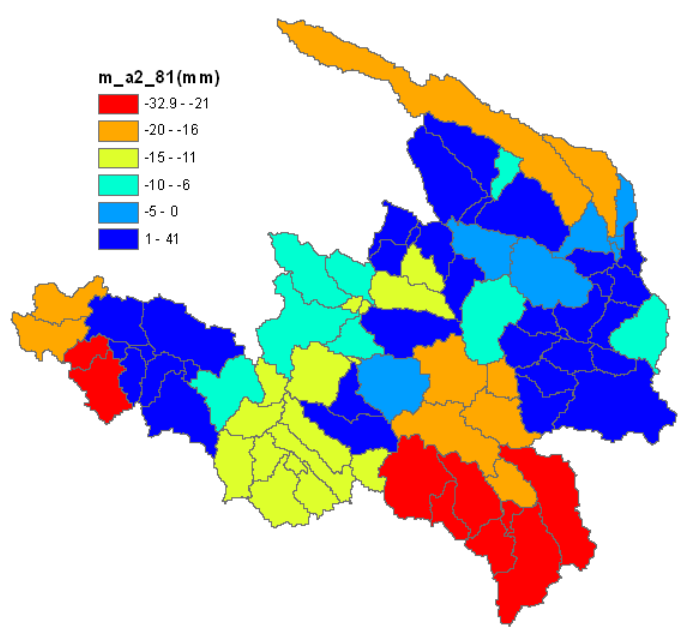

(c)

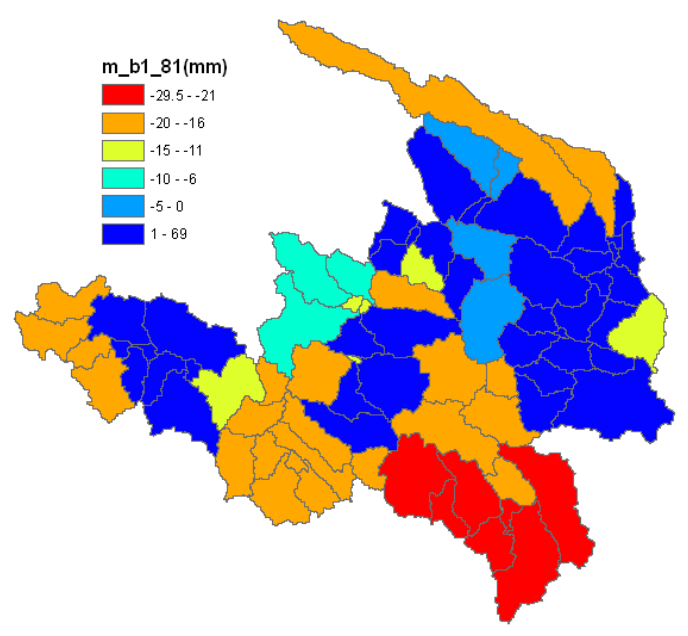

(d)

Figure 15. MRI-estimated spatial distribution of mean annual runoff depth in sub-basins for 20462065 ( $a$ and b) and 2081-2100 (c and d) compared to baseline period

\section{Conclusions}

As an important component of the climate system, the water cycle is extremely sensitive to climate change. This has been a frequent topic and emphasis in the investigation of the effects of climate change on the basin water cycle and water resources [49]. In the present study, taking the typical basins of the Yangtze and Yellow River basins as objects, we conducted suitability assessments of GCMs and downscaling. Through coupling of GCMs and distributed hydrological models, the influence of climate change on the basin water cycle was quantified. The conclusions are as follows.

(1) Based on rank scoring, the degree of fit between statistical values of GCM output and those of reanalysis data was taken as the objective function. Scores were given according to the performance of every objective function, thereby obtaining comprehensive scores for the performance of each GCM in their simulation of the Yangtze and Yellow River basins. Specifically, the top three models were the MRI, HadGEM1 and INM for the Yangtze River, and FGOALS, ECHAM4 and ECHAM5 for the Yellow River. This indicates a substantial difference between the southern and northern regions of China with respect to the effects of climate change.

(2) Future precipitation and temperature data under the A1B scenario were generated by the ASD downscaling model, which were used to drive the VIC model on $5 \mathrm{~km} \times 5 \mathrm{~km}$ grids. Simulation of hydrologic processes in the Taihu basin on the lower reaches of the Yangtze River showed that areas with substantial reduction in runoff depth during 2046-2065 compared to a baseline period were western Zhejiang and Hangzhou-Jiaxing-Huzhou. The western Zhejiang area showed a slight increase in runoff depth during flood season. Runoff depth in western Zhejiang tended to decrease in 2081-2100 compared to the baseline period, but this decrease was less than that during 2046-2065.

(3) The SWAT model gave relatively promising results for the upper reaches of the Yellow River basin. Under the A2 and B1 scenarios, basin runoff tended to decrease in future periods. In particular, the decrease was greater in 2081-2100 than in 2046-2065. Under different scenario combinations, multiyear average runoff in 2046-2065 and 2081-2100 was 27.507 and 25.737 billion $\mathrm{m}^{3}$, respectively, reductions of $16.9 \%$ and $22.2 \%$ compared to the baseline period. Under various scenario combinations, spatial runoff variation in the upper basins of the Yellow River was consistent. In most areas there was a decreasing tendency in runoff depth. Specifically, the decrease was largest in Hongyuan, Jiuzhi and Ruoergai, in excess of $20 \mathrm{~mm}$. Maximum runoff decrease did not vary much with the scenario combination, and was about $-30 \mathrm{~mm}$. However, the magnitude of increase was substantially different, between 12.7 and $69 \mathrm{~mm}$. 
In view of the complexity and uncertainty of climate change and the basin water cycle, future work should focus on the following aspects on the basis of the most recent AR5 outcome.

(1) Detection and attribution of continental water cycle, multi-element spatiotemporal variation, to reveal the mechanism of water cycle response to climate change.

(2) Development of probability prediction theory and methods of future hydrologic scenario change, quantitative analysis of uncertainty of the effects of climate change on water resources, and risk management and decision-making for water resources.

(3) Development of new-generation, large-scale, distributed continental water cycle simulation systems, thereby achieving atmospheric-hydrologic coupling and revealing the mechanism of interaction between climate change, human activity, and the water cycle.

(4) Evaluation theory and methods for water resource vulnerability to climate change, thereby providing a basis for regulating adaptive countermeasures for climate change.

Acknowledgements: This work was jointly supported by Natural Sciences Foundation of China (51509247, 91425302 and 91225301), Special Fund for Agro-scientific Research in the Public Interest (201203077), and Specialized Research Fund for the Doctoral Program of Higher Education (20130008120005). Assistance from the colleagues in the China Institute of Water Resources and Hydropower Research, Taihu Basin Authority and Chinese Academy of Agricultural Sciences are gratefully acknowledged as well who kindly provided valuable data and advice that greatly improved the quality of the paper.

Author Contributions: Liu Liu and Zongxue Xu conceived and designed the framework of this study; Liu Liu Rong Li and Youzhi Wang collected and processed the data; Liu Liu constructed and calibrated the model, analysed the results and wrote the paper. All authors have proofread and approved the final manuscript.

Conflicts of Interest: The authors declare no conflict of interest.

\section{References}

1. Stocker, T.F.; Qin, D.; Plattner, G.-K.; Tignor, M.; Allen, S.K.; Boschung, J. IPCC 2013: Climate Change 2013: The Physical Science Basis. Contribution of Working Group I to the Fifth Assessment Report of the Intergovernmental Panel on Climate Change; Cambridge University Press: Cambridge, UK, 2013.

2. Qin, D.H. Facts, Impact, Adaptation and Mitigation Strategy of Climate Change. Bulletin of National Natural Science Foundation of China 2003, 17, 1-3.

3. Qin, D.H.; Chen, Z.L.; Luo, Y.; Ding, Y.H.; Dai, X.S.; Ren, J.W.; Zhai, P.; Zhang, X.Y.; Zhao, Z.C.; Zhang, D.E.; Gao, X.J.; Shen, Y.P. Updated Understanding of Climate Change Sciences. Advances in Climate Change Research 2007, 3, 63-73.

4. Hadson, D.A.; Jones, R.G. Regional climate model simulations of present-day and future climates of southern Africa. Hadley Centre Technical Note 39; Hadley Centre for Climate Prediction and Research, Met Office: London Road, Bracknell, UK, 2002.

5. Varis, O.; Kajander, T.; Lemmelä, R. Climate and Water: From Climate Models to Water Resources Management and Vice Versa. Climatic Change 2004, 66, 321-344.

6. Burn, D.H.; Sharif, M.; Zhang, K. Detection of trends in hydrological extremes for Canadian watersheds. Hydrological Processes 2010, 24, 1781-1790.

7. Elfert, S.; Bormann, H. Simulated impact of past and possible future land use changes on the hydrological response of the Northern German lowland "Hunte" catchment. Journal of Hydrology 2010, 383, 245-255.

8. Karamouz, M.; Noori, N.; Moridi, A.; Ahmadi, A. Evaluation of floodplain variability considering impacts of climate change. Hydrological Processes 2011, 25, 90-103.

9. Jung, I.W.; Chang, H. Assessment of future runoff trends under multiple climate change scenarios in the Willamette River Basin, Oregon, USA. Hydrological Processes 2011, 25, 258-277.

10. Liu, Q.; McVicar, T.R. Assessing climate change induced modification of Penman potential evaporation and runoff sensitivity in a large water-limited basin. Journal of Hydrology 2012, 464, 352-362.

11. Marvel, K.; Bonfils, C. Identifying external influences on global precipitation. Proceedings of the National Academy of Sciences of the United States of America (PNAS) 2013, 110, 19301-19306. 
12. Piao, S.; Ciais, P.; Huang, Y.; Shen, Z.H.; Peng, S.S.; Li, J.S.; Zhou, L.P.; Liu, H.Y.; Ma, Y.C.; Ding, Y.H.; Friedlingstein, P.; Liu, C.Z.; Tan, K.; Yu, Y.q.; Zhang, T.Y.; Fang, J.Y. The impacts of climate change on water resources and agriculture in China. Nature 2010, 467, 43-51.

13. The writing committee of the second national evaluation report on climate change. The second national evaluation report on climate change. Beijing: Science Press, 2011.

14. Ye, D.Z.; Huang, R.H. Pattern and causes of draught and waterlogging in Yellow River and Yangtze River basins. Jinan: Shangdong Science and Technology Press, 1996.

15. Fu, C.B.; An, Z.S.; Guo, W.D. Evolution of Life-Supporting Environment in Our Nation and The Predictive Study of Aridification in Northern China (I): Main Scientific Issues and Achievements. Advances in Earth Sciences 2005, 20, 1157-1167.

16. Ding, Y,H; Ren G.Y. An introduction to climate change science in China. Beijing: China Meteorological Press, 2008.

17. Ding, Y.H, Ren, G.Y., Shi, G.Y., Gong, P.; Zheng X.H.; Zhai, P.M.; Zhang, D.E.; Zhao, Z.C.; Wang, S.W.; Wang, H.J.; Luo, Y.; Chen, D.L.; Gao, X.J.; Dai, X.S. National Assessment Report of Climate Change (I): Climate change in China and its future trend. Advances in Climate Change Research 2006, 2, 3-8.

18. Chen, Z.K. Sustainable drought and water crisis in North China. China Water Resources 2002, 4, 8-11.

19. Liu, C.M. Study of some problems in water cycle changes of the Yellow River basin. Advances in Water Science 2004, 15, 608-614.

20. Qian, Z.Y.; Shen G.F.; Shi, Y.L. Several strategic issues related to land and water resource allocation, ecological and environmental protection and sustainable development in Northeast China (comprehensive volume). Beijing: Science Press, 2007.

21. Qiu, X.F.; Liu C.M.; Zeng, Y. Changes of pan evaporation in the recent 40 years over the Yellow River Basin. Journal of Natural Resources 2003, 18: 437-442.

22. Yang, J.P.; Ding, Y.J.; Chen, H.S.; Liu, L.Y. Variations of Precipitation and Evaporation in North China in Recent 40 Years. Journal of Arid Land Resources \& Environment 2003, 17: 6-11.

23. Liu, B.H.; Xu, M.; Henderson, M.; Gong, W. A spatial analysis of pan evaporation trends in China, 1955-2000. Journal of Geophysical Research Atmospheres 2004, 109, 1255-1263.

24. Ren, G.Y.; Guo, J. Change in Pan Evaporation and the Influential Factors over China: 1956-2000. Journal of Natural Resources 2006, 21, 31-44.

25. Wang, G.Q.; Wang, Y.Z.; Kang, L.L. Analysis on the Sensitivity of Runoff in Yellow River to Climate Change. Journal of Applied Meteorological Science 2002, 1, 117-121.

26. Liu, C.Z. The Advances in Studying Detection of Streamflow Trend Influenced by Climate Change. Advances in Earth Science 2007, 22, 777-783.

27. Zhang, J.Y.; Liu, J.F. A model to evaluate and analyze the effect of climate anomalies on water resources. Advances in Water Science 2000, 11, 1-9.

28. Xia, J.; Thomas T.; Ren, G.Y.; Cheng, X.T.; Wang, J.X.; Wang, Z.J.; Yan, M.C.; Liu, X.J.; Ian, H. Potential Impacts of Climate Change on Water Resources in China: Screening for Adaptation and Management. Advances in Climate Change Research 2008, 4, 215-219.

29. Lin, E.D.; Xu, Y.L.; Jiang, J.H.; Li, Y.E.; Yang, X.; Zhang, J.Y.; Li, C.X.; Wu, S.H.; Zhao, Z.Q.; Wu, J.G.; Ju, H.; Yan, C.R.; Wang, S.R.; Liu, Y.F.; Du, B.L.; Zhao, C.Y.; Qin, B.F.; Liu, C.Z.; Huang, C.Y.; Zhang, X.Q.; Ma, S.M. National Assessment Report of Climate Change (II): Climate change impacts and adaptation. Advances in Climate Change Research 2006, 2, 51-56.

30. Wang, S.R.; Zheng, S.H.; Cheng, L. Studies on Impacts of Climate Change on Water Cycle and Water Resources in Northwest China. Climatic and Environmental Research 2003, 8, 43-51.

31. Wilby, R.L.; Dawson, C.W.; Barrow, E.M. SDSM-A decision support tool for the assessment of regional climate change impacts. Environmental Modelling \& Software 2002. 17, 145-157.

32. Hessami, M.; Gachon, P.; Ouarda, T.B.M.J.; St-Hilaire, A. Automated regression-based Statistical Downscaling tool. Environmental Modelling and Software 2008, 23, 813-834.

33. Xu, Z.X.; Liu, P.; Liu, W.F. Automated statistical downscaling in several river basins of the Eastern Monsoon region, China. Proceedings of H01, IAHS-IAPSO-IASPEI Assembly, Gothenburg, Sweden, 2013 (IAHS Publ. 359, 2013), 80-85

34. Yuan, F.; Xie, Z.H.; Ren, L.L.; Huang, Q. Hydrological variation in Haihe River Basin due to climate change. Journal of Hydraulic Engineering 2005, 36, 274-279. 
35. Liu, Q. Application of the VIC large scale land surface hydrologic model in China. Ph.D., Hunan University, Changsha, China, 2004.

36. Su, F.G.; Xie, Z.H. A model for assessing effects of climate change on runoff in China. Progress in Natural Science 2003, 13, 701-707.

37. Lohmann, D.; Raschke, E.; Nijssen, B.; Lettenmaier, D.P. Regional scale hydrology: II. Application of the VIC-2L model to the Weser River, Germany. Hydrological Sciences Journal 1998, 43, 143-158.

38. Nijssen, B.; Lettenmaier, D.P.; Liang, X.; Wetzel, S.W.; Wood, E.F. Streamflow Simulation for Continental-Scale River Basins. Water Resources Research 1997, 33, 711-724.

39. Abdulla, F.A.; Lettenmaier, D.P.; Wood, E.F.; Smith, J.A. Application of a macroscale hydrologic model to estimate the water balance of the Arkansas-Red River Basin. Journal of Geophysical Research Atmospheres 1996, 101, 7449-7459.

40. Arnold, J.G.; Srinivasan, R.; Muttiah, R.S.; Williams, J.R. Large area hydrologic modeling and assessment Part I: Model development. Journal of the American Water Resources Association 1998, 34, 73-89.

41. Neitsch, S.L.; Arnold, J.G.; Kiniry, J.R.; Williams, J.R. Soil and Water Assessment Tool Theoretical Documentation Version 2005. Temple, Texas: Grassland, Soil and Water Research Laboratory, Agricultural Research Service, Blackland Research Center, Texas Agricultural Experiment Station, 2005.

42. Zhang, Z.X.; Jiang, T.; Zhang, J.C.; Zhang, Q.; Liu, X.F. Spatial-temporal properties of moisture budget and associated large-scale circulation in the Yangtze River Basin. Journal of Lake Sciences 2008, 20, 733-740.

43. Xu, Y.; Ding, Y.H.; Zhao, Z.C. Detection and Evaluation of Effect of Human Activities on Climatic Change in East Asia in Recent 30 Years. Journal of Applied Meteorological Science 2002, 13, 513-525.

44. Maxino, C.C.; Mcavaney, B.J.; Pitman, A.J.; Perkins, S.E. Ranking the AR4 climate models over the Murray-Darling Basin using simulated maximum temperature, minimum temperature and precipitation. International Journal of Climatology 2008, 28, 1097-1112.

45. Cao, Y.; Zhang, G.H. Applicability Evaluation of Global Circulation Models in the Yellow River Basin. Journal of China Hydrology 2009, 29, 1-5.

46. Zhou, X.X.; Ding, Y.H.; Wang, P.X. Moisture transpotr in Asian summer monsoon region and its relationship with summer precipitation in China. Acta Meteorologica Sinica 2008, 66, 59-70.

47. Chu, Q.; Xu, Z.X.; Jiang, X.H. Comparison of Two Statistical Downscaling Methods in the Taihu Basin. Resources Science 2012, 34, 2323-2336.

48. Liu, L.; Xu, Z.X.; Huang, J.X. Impact of Climate Change on Runoff in the Taihu Basin. Journal of Beijing Normal University(Natural Science) 2010, 46, 371-377.

49. Xu, Z.X.; Liu, L.; Liu, Z.F. Impacts of climate change on river basin water cycle. Beijing: Science Press, 2015.

(C) 2016 by the authors; licensee Preprints, Basel, Switzerland. This article is an open access article distributed under the terms and conditions of the Creative Commons by Attribution (CC-BY) license (http://creativecommons.org/licenses/by/4.0/). 